\title{
THE DEVELOPMENT OF UNEVENAGED STANDS OF ENGELMANN SPRUCE, AND PROBABLE DEVELOPMENT OF RESIDUAL STANDS AFTER LOGGING.
}

\author{
BX G. H. BARNES
}

\section{INTRODUCTION}

$\mathrm{T}$

HE spruce-balsam (P. engelmannii, P. canadensis, A. lasiocarpa) forest type of the central interior of British Columbia is one of the major timber types of the province. It occupies, more or less completely, an area in excess of 50,000 square miles extending from the Alberta Boundary west to the vicinity of Stuart Lake, and from the Peace River country south to the Quesnel Lake region, coinciding approximately with the area of the Prince George Forest District. No statement is available of the total stand in this type but it is very large. The estimated total stand of merchantable timber in the Prince George District is about 33 billion board feet (1) of which 21 billion (64\%) are spruce and $51 / 4$ billion (16\%) are Balsam.

The natural stand in this type is composed almost exclusively of Spruce and Balsam in uniform mixture in the proportions by net volume of about 80 per cent. Spruce and 20 per cent. Balsam. All age classes are represented in the typical forest. Spruce ranges in age up to about 350 years and Balsam up to 250 years. The Spruce is characteristically sound and of fine quality. Balsam is characteristically decayed. Dickson has found that, while the Balsam is usually sound up to 100 years in age, it deteriorates rapidly thereafter and he estimates that on the whole it is subject to more than 50 per cent. defect.

The net merchantable volume per acre averages about 14,500 board feet of Spruce and 3,500 board feet of Balsam.

In 1914 the Grand Trunk Railway, now (1935) the Canadian National, was completed through the centre of this region and immediately following there developed a substantial logging and sawmill business which has proved to be the mainstay of the business life of that part of the province.

This Spruce-Balsam type constitutes one of the principal timber reserves of the province. It has been, and must continue to be the mainspring of development of a very large area.

Natural regeneration under the mature overstory which is left as a residual stand after logging is fairly satisfactory so far as mere stocking is concerned, but as shown by Barr (3), (4), and Griffith (5), the incidence of species is greatly in favor of Balsam. By number of trees Balsam forms about 
80 per cent. and Spruce only 20 per cent. of the residual stand. This proportion can be governed by exposing a seed bed of mineral soil for some time previous to logging which is conducive to the germination and survival of new Spruce seedlings. This operation would be too costly, however, to include in any practical management plan at the present time.

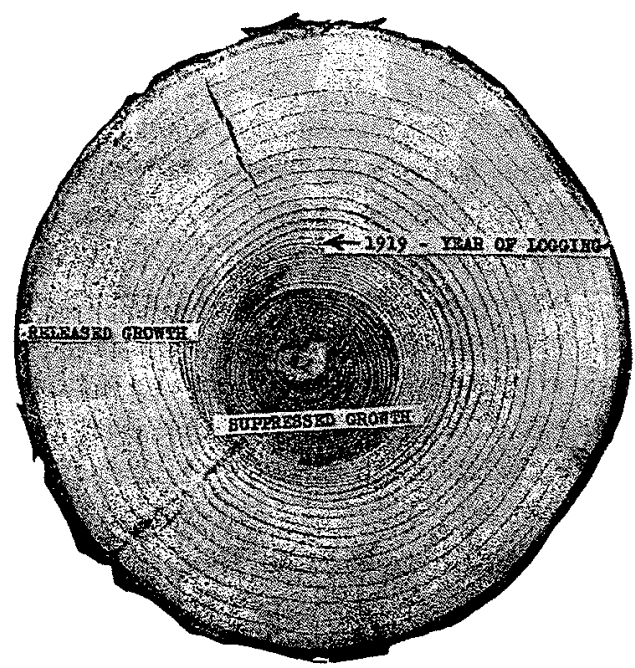

PLATE I.

Typical cross section of an Engelman Spruce stem of the mature virgin stand, showing periods of suppressed and released growth.

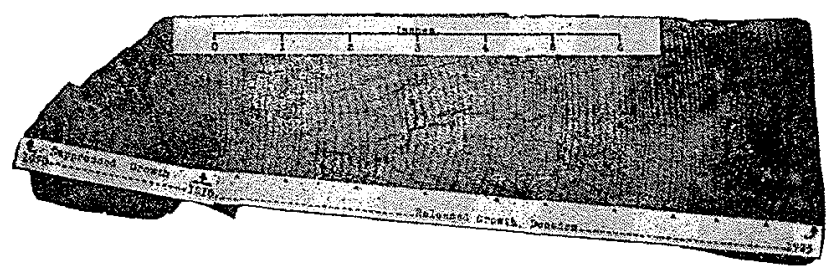

PLATE II.

Typical cross section of an Engelmann Spruce stem released from competition by logging in 1919. A marked acceleration in growth began immediately following release.

The natural composition of the residual stand has been considered inadequate for the production of a subsequent crop of Spruce, and improvement of seed bed conditions to favor this species has been deemed necessary for a satisfactory result. This being true, the question arises as to how suitable conditions materialized for the development of the present mature 
stand, which introduces the possibility of other factors in its development extraneous to seed bed conditions and early regeneration.

Graham (6), in writing of the Spruce-Balsam forests of Eastern Canada, points out that the cut-over stands in this type consist predominately of Balsam in their youth, but says, "There is some reason for supposing that the proportion of Spruce in the mixture increases with the age of the stand." Baker (7), referring to Spruce-Fir forests of the Eastern United States says, "If these stands were grown on a long enough rotation, the Spruce would undoubtedly replace the Fir . ..."

With the foregoing concepts in mind it is the purpose of this investigation to arrive at information relative to:-

(1) The development of the present mature stands and their present growth tendencies.

(2) The probable development of residual stock on cut-over lands and expectations as to ultimate yield.

(3) Sound methods of management designed to maintain both productivity and a large proportion of Spruce.

\section{BASIC DATA}

The data on which this study is based were obtained at the Aleza Lake Forest Experiment Station from a series of 17 permanent plots of 0.4 acres each, 4 of which were established in cut-over type in 1926, and 13 in the mature uncut type in 1928. Subsequent examinations were made in 1931 and 1934 on the cut-over plots, and in 1933 on the mature uncut plots. In addition a series of mechanically selected temporary plots were established and examined in 1934.

The 13 plots in the mature uncut type were originally established in conjunction with a study relative to the establishment of reproduction in this type on sites where Balsam and Spruce reproduction was relatively abundant. The distribution of stems in the smaller d.b.h. classes on these plots therefore tends to be abnormally high in relation to average conditions. The remaining 4 plots in the cut-over type, were hardly sufficient to give an accurate distribution of stems in the residual stands. In order to arrive at representative distributions of stems before and after cutting the mechanically selected temporary plots were established on recently logged areas, and in uncut stands adjacent to them.

Data recorded on the permanent plots at time of establishing were as follows:-

1. D.b.h., total height and age of every tree 4 inches d.b.h. and over in the uncut type, 1 inch and over in the cut-over type. 
2. Increment by decades measured from increment cores, over the entire life of the tree in the mature uncut type, and over 17 years in the cut-over type ${ }^{1}$.

3. Number of trees on small sub-plots, by total height classes, less than 4 inches in the uncut type, less than 1 inch in the cut-over type.

On re-examination, the following data were recorded:

1. D.b.h., total height, and crown class of each of the original trees over 4 inches and 1 inch in the uncut and cut-over types respectively.

2. Mortality with an attempt to ascribe the cause.

On the temporary plots all trees under 15 inches were tallied by d.b.h. classes in both the cut-over and uncut types. 15 inches approaches the maximum d.b.h. limit on the cut-over type, and for the distribution of trees above this limit in the uncut type adequate data were available from strip cruise tallies.

\section{DEVELOPMENT AND GROWTH OF THE MATURE STAND DIAMETER INCREMENT OF SPRUCE}

An analysis of the increment core measurements discloses a period of accelerated growth beginning in the two decades $1798-1818,130$ to 110 years prior to measurements. Similar favourable growth periods have been noted by Dwight (8) who considers them to be the result of release by heavy windfall.

In order to examine the growth trend following the start of acceleration the mean increment of all trees was determined for successive 20-year periods beginning at 1808 which marks the mid point of the period in which acceleration began. These increment values were plotted over their respective periods as shown in Figure 1. The curve indicates a growth rate prior to 1808 constant at a value of 1.3 to 1.4 inches per 20-year period. Following this it increased during the succeeding 40 years to a maximum of 2.4 inches, and thereafter falls off slowly over a period of 80 years to the original value of about 1.3 inches in 1928.

This growth history suggests a cyclic development of these unevenaged stands. It would appear that the dominant, or older age classes, have developed at a rapid rate of growth to maturity and full crown cover at the same time suppressing the younger age classes. Maturity in these dominants has been marked by a comparatively short period of slow constant growth, followed by rapid weakening and thinning by disease, windthrow, or insects, resulting in a quick opening up of the stand to start 1Plots in the cut-over type were established 7 years after cutting occurred. The 17 years
of increment were divided into 10 years prior to cutting and 7 years subsequent to cutting. 
Fig. 1

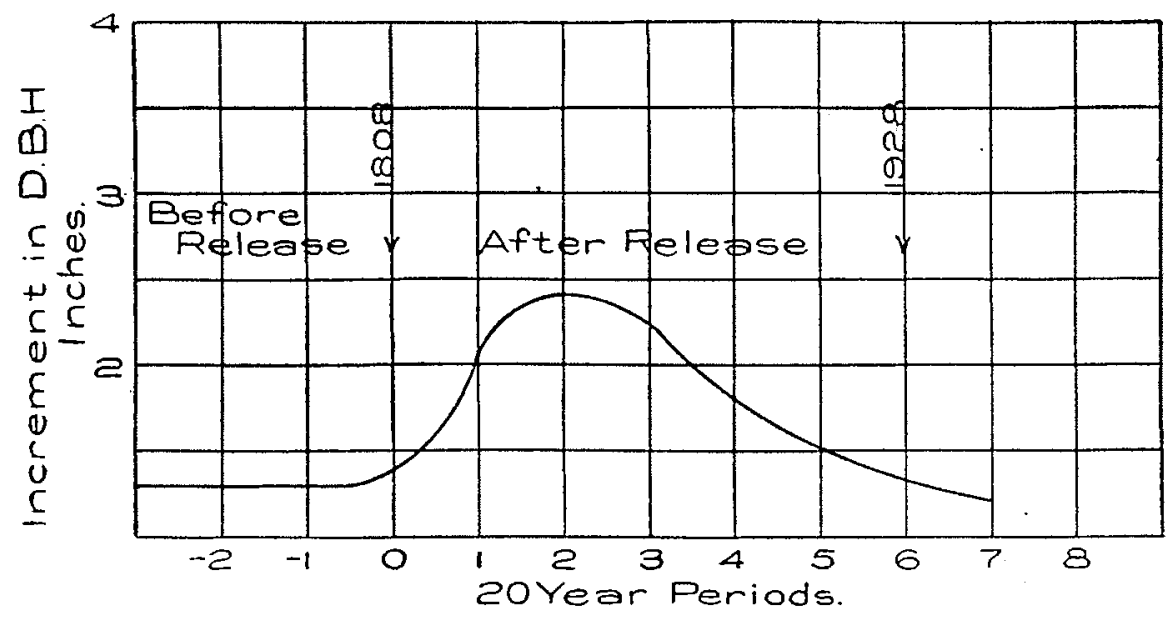

The trend of 20 Year periodic diameter - increments of Spruce of the mature stand, showing the acceleration which took place subsequent to 1808 .

the cycle again by the release of inherent dominants in the younger understory.

The mature overstory of the stands at Aleza Lake seem to have just reached the maximum age of maturity. That a period of depletion may be expected at any time is further borne out by the fact that there has been heavy windfall in recent years on large areas of similar forest growth in the vicinity of the Experiment Station.

\section{Basal Area Increment on Permanent Plots}

A comparison of plot measurements of 1928 with the measurements of 1933 affords a further indication that the dominant element in these stands has reached maturity, and that a loss in total stock may be expected at an early date. The sum of the basal areas of all trees 5 inches and over on the 13 permanent plots in the uncut type was 547.31 square feet in 1928 , and 551.10 square feet in 1933 , a gain of only 3.79 square feet. The comparison is best brought out by an examination of Table 1 in which the basal area of each plot measurement is tabulated. It will be noted that over the 5-year period seven of the plots show an increase in basal area and six of them a decrease. When statistical tests are applied (See appendix i), the small increase of 3.79 square feet is found to be of little significance and may be due merely to chance. It is therefore probable, as far as we 
can say from the data at hand, that the basal area is practically stationary at the present time, and that increases in individual trees have been offset by losses due to mortality.

TABLE 1.

Comparison of Basal Areas of Spruce Including All Trees 5 Inches and Over Between 1928 and 1933 on 13 Sample Plots of 0.4 Acres.

Plot No.

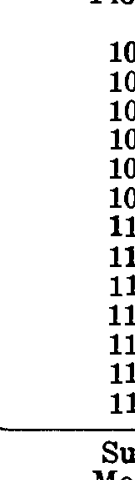

Basal Area

1928
32.82

34.02

34.27

29.64

38.06

35.93

33.45

51.91

23.72

60.12

52.13

65.51

55.73

547.31

42.10
1933

33.28

35.13

34.29

29.14

39.09

36.95

31.51

51.51

26.62

59.66

52.04

62.59

59.29
Difference

$$
\begin{array}{r}
+.46 \\
+1.11
\end{array}
$$

+1.11
+.02
+.50

+.50
+1.08

$$
\begin{array}{r}
+1.03 \\
+1.02
\end{array}
$$

+1.02
-1.94

$-.40$

$+2.90$

$-.46$

.09
-.09

$-2.92$ $+3.56$

$+3.79$

+3.79
$+\quad .29$
Diff. in per-
cent. of 1928

+1.4
$+\quad 3.3$

+
$+\quad 0.1$

$+1.7$

$\begin{array}{r}+2.7 \\ \hline\end{array}$

$+2.8$

$-5.8$

$-\quad .8$

$+12.2$

$-\quad .8$

$-\quad .2$ $+6.3$

$+15.0$

42.39

\section{PROBABLE DEVELOPMENT AND EXPECTED YIELD OF} RESIDUAL STANDS ON CUT-OVER TYPES

\section{Condition of Cut-over Stands}

In logging the mature stand, all the merchantable trees of the upper story are removed down to a minimum diameter limit of roughly 12 inches breast height, and although some of the smaller trees and reproduction are damaged or completely destroyed during the operation, there is still a fair residual stand left on the ground. Most of the damage occurs on the skid roads and decking sites, where the understory is almost totally destroyed. On charting the areas so denuded it was found that they comprise approximately 15 per cent. of the area logged. Immediately after logging the extent of these areas looms particularly large, but in the course of a few years, with the growth of the bordering trees, the smaller openings at least become less apparent.

On two representative areas recently logged and sampled by means of plots mechanically distributed the residual stand was made up as follows:

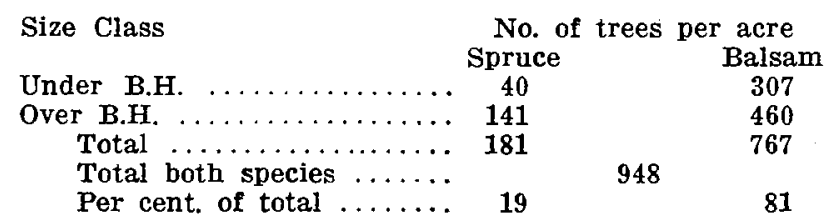


Of the total 948 trees approximately 20 per cent. are Spruce and 80 per cent. are Balsam. The obvious inference is that the mature crop to be produced from these will show the same deficiency in Spruce. It develops later in this study, however, that, due to differences in the mortality rate of the two species, it is likely that the young stand will produce a mature growth predominantly Spruce. If the natural thinning of 120 years ago is granted it is probable that the present mature stands, about 80 per cent. Spruce by net volume, developed from an understory very similar in composition to that existing on cut-over areas, and in the younger age classes of uncut stands of to-day.

On the cut-over areas examined were found 181 Spruce per acre below 12 inches d.b.h. On adjacent uncut areas there are 278 below the same diameter limit. Apparently about 65 per cent. of the original Spruce understory survives present logging methods. This value could be materially increased if some care were exercised to protect the understory during logging operations.

Distribution of Spruce by diameter classes for cut-over and uncut types is shown in Figure 2.

The distribution of trees in the uncut stands is of the usual J-shaped form characteristic of unevenaged stands, with relatively large numbers of trees in the smaller diameter classes but, contrary to the general rule, the curve is of a bimodal form having a peak at values of 0 and 14 inches. It was thought at first that the bimodal characteristic might be due to a scarcity of trees of certain age classes, which in turn would account for the apparent scarcity of trees in diameter classes around 10 inches. To test this explanation the trees of the 13 individual permanent plots of the uncut type, which show the same bimodal form in their stem distribution, were classified by diameter-age classes. All age classes appeared to be normally represented, denying the explanation given. It was not until much later on in the investigation that the significance of the bimodal dis. tribution was finally determined.

\section{STAND Types}

Up to this point the data presented relative to the residual stands have covered conditions as a whole over the two areas examined. These two areas represent two distinct soil types which may be recognized generally throughout the forest. The soil of one is a clay, and the other a brown loam. The clay type is usually distinguished by a relative abundance of Lonicera and Corylus sp., the loam by a relative abundance of Fatsia and Aspidium sp. 
Fig. 2

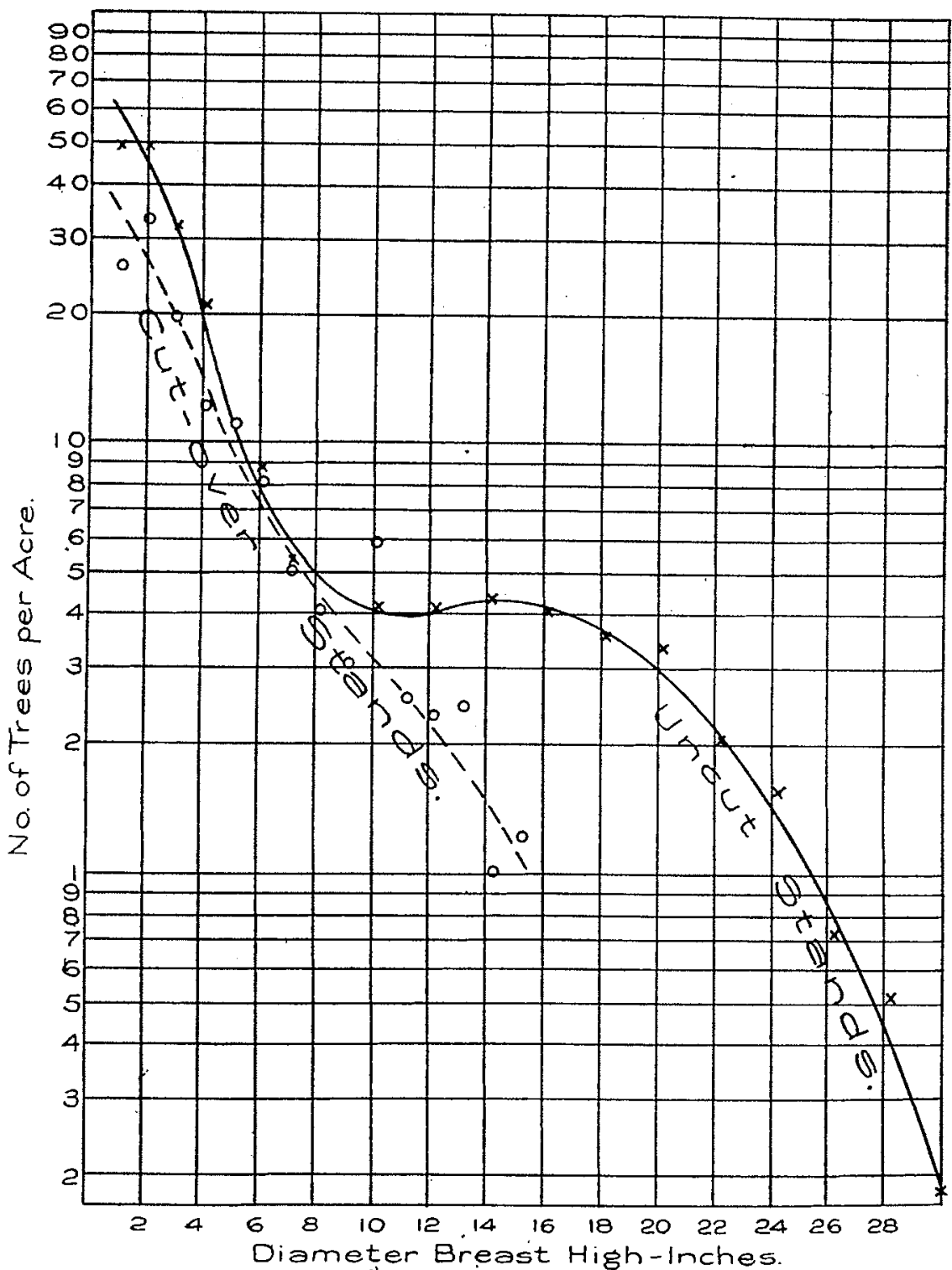

Average number of Spruce Trees per Acre by one-inch diameter classes over two cut-over areas, and on the mature uncut areas contiguous to them. 
There are about the same number of Spruce stems per acre on the two soil types but the distribution of diameter classes differs as shown in Figure 3. There are relatively more trees in the smaller and larger diameter classes on clay and loam respectively. In the case of balsam a greater number of stems per acre are found on clay than on loam. These differences in stem distribution will mean differences in ultimate yield values, and for this reason the two types are considered separately hereafter in yield calculations.

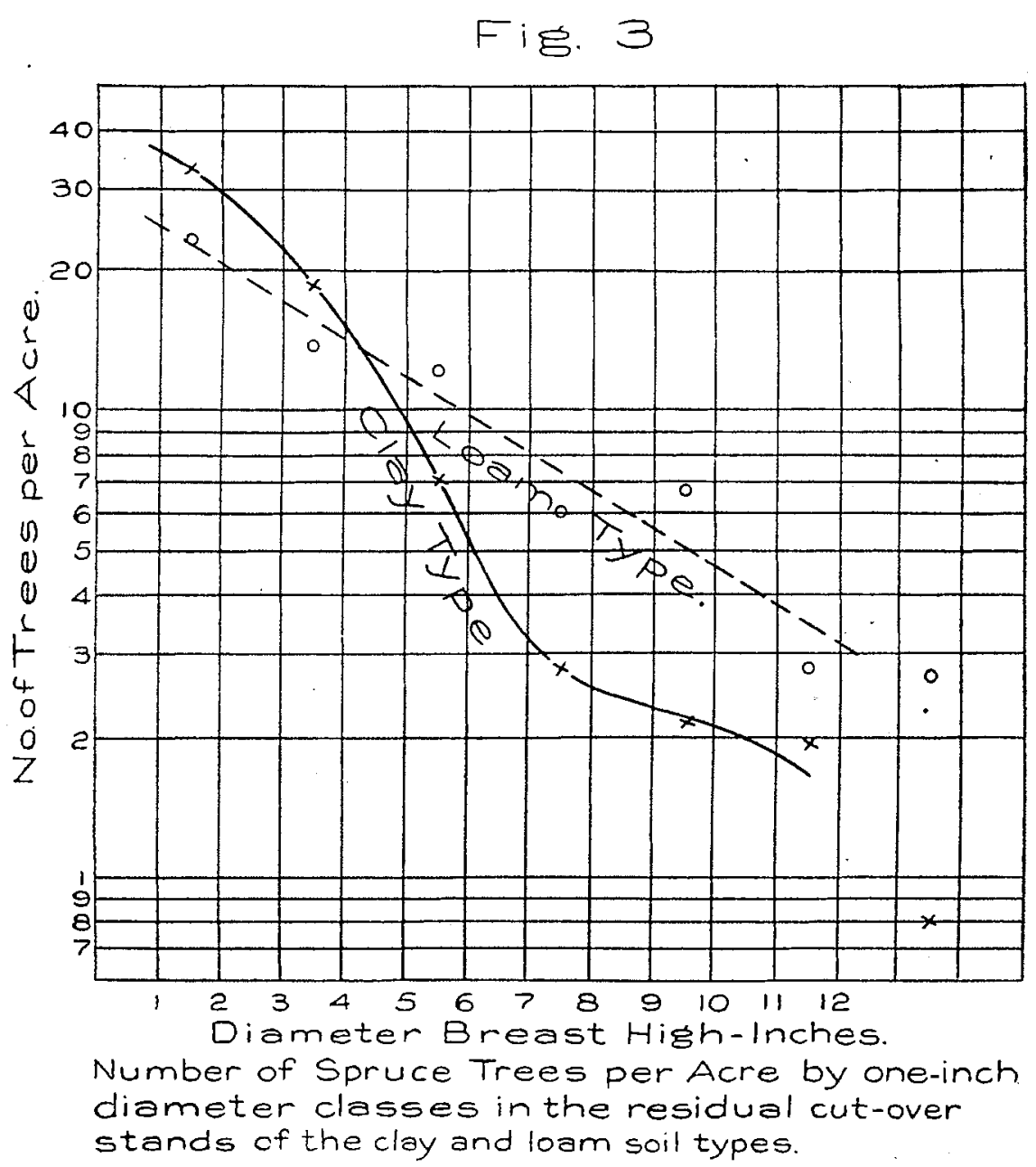


The eventual yield of these stands depends upon four major considerations:-

1. The amount of increment added by the individual trees over a given period of time.

2. The mortality occurring during the same period.

3. The number and size of new trees entering the stand during that period.

4. Soil type.

\section{DIAMETER INCREMENT IN SPRUCE}

The Basis of Estimating InCRement in the Cut-over Stands

It has been shown that, during a period centered around 120 years ago, some event occurred to cause a rapid acceleration in the increment of the trees in the present mature stand, the history of which has been traced. The same relative growth tendency may be expected in the residual stands recently released in logging the mature overstory, although differences in absolute value might develop due to differences in the extent of release.

If some means could be found of estimating the growth of the mature stands after the start of accelerated increment 120 years ago, the same means, modified to account for differences, might be used in estimating the future growth of cut-over stands.

An attempt was made to estimate the diameter increment of the trees of the mature stand subsequent to release, by correlations of increment with diameter and age of the trees at the time of release. If satisfactory correlations based on either or both of these factors could be derived, growth charts (9) might be constructed from which diameters of the trees at subsequent dates could be read. These charts could then be modified to suit present day conditions in the cut-over type, and serve for the prediction of their growth.

It was found however that so far as these two factors were concerned increment added in a given time was very much a matter of chance.

A second trial was made by adding to the base diameter of each tree of the released stand the small amount of increment which did prove to be correlated with its diameter, and a further amount varying in accordance with the distribution of the residual ${ }^{2}$ increment remaining after the amount dependent on diameter had been accounted for. This process proved to be satisfactory. It does not pretend to estimate the future diameter of

2"Residual," as used in connection with increment is merely that part of the grosg increment remaining after the part due to diameter has been accounted for. It has no direct relation to its use in connection with "Residual" stands. 


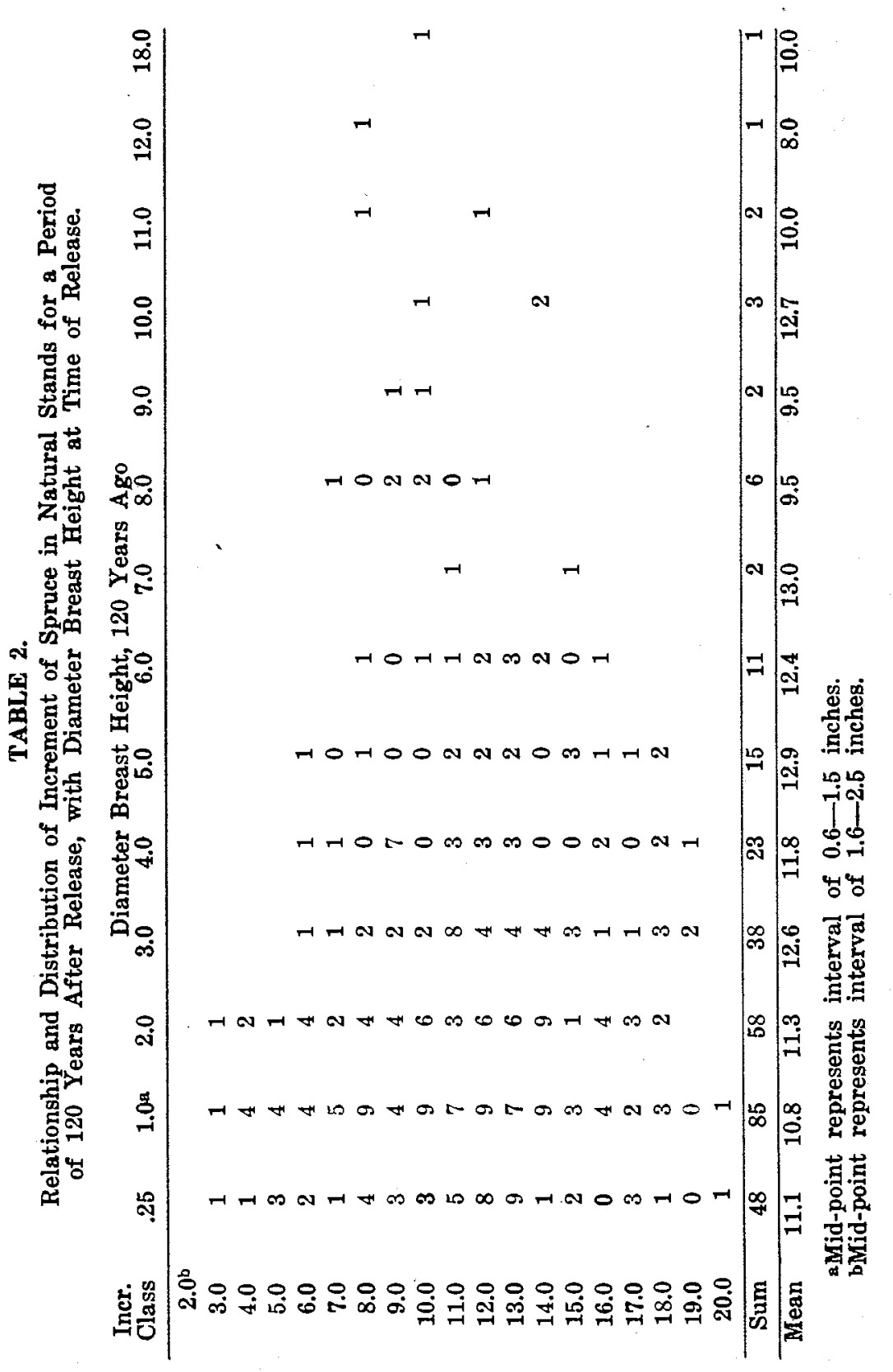


any individual tree, but it does give the probable future stem distribution of the trees of a stand when a large number of trees are involved.

Diameter Increment in Mature Stands Following Release

The mean periodic diameter increments for successive 20-year periods have been derived and are shown in Figure 1. If these values are summed cumulatively the total mean increment at the end of each successive 20. year period after release is obtained. These values are termed hereafter the Mean Gross Increment.

Table 2 shows the gross increments added by trees of different diameter classes for a period of 120 years after release, and the mean increment of all trees for the period shows a value of 11.4 inches.

On further examining Table 2, it will be noted that there is little correlation between the diameter of the trees at the time when thinning occurred, i.e., between the diameter of the trees 120 years ago and the increment added over that period. If the means of the vertical columns are calculated however, as is shown in the table, and plotted over their respective diameter classes as in Figure 4, it is evident that there is some correlation present, especially in the smaller diameter classes. A curve through the plotted points indicates that the smaller trees and larger trees have grown a little more slowly than the middle sized trees. The curve cuts the 0 -diameter axis at a value of 10.4 inches, rises to a value of 12.7 inches for 6 inch trees and thence falls off again; so that during the 120-year period all the trees have grown an average of 10.4 inches plus an extra amount which is dependent on the diameter of the tree at time of release.

$$
\text { Fig. } 4
$$

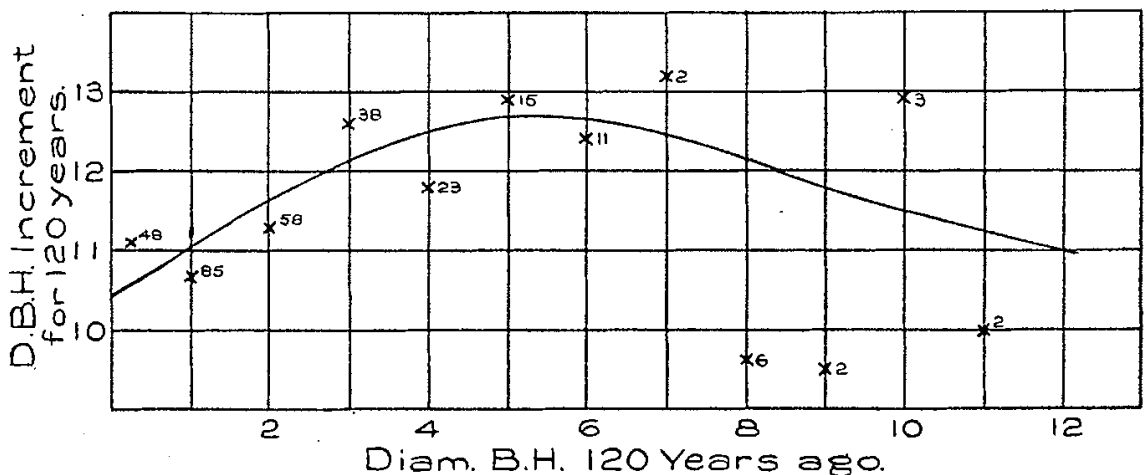

Showing the extent to which increment of Spruce in mature stands over a period of 120 years after release is correlated with D.B.H. at time of release. 


\section{ENGELMANN SPRUCE-BARNES}

These plus values for the different diameter classes are the differences between 10.4 and the curve value for the diameter classes. For instance, the plus value for the 6 inch diameter class is,

$$
\begin{array}{cccccc} 
& \multicolumn{1}{c}{12.7-10.4=2.3 \text { inches, }} \\
\text { for the } 2 & \text { inch class } 11.6-10.4=1.2 \text { inches, } \\
\text { " } & \text { " } & 4 & \text { " } & \text { " } & 12.5-10.4=2.1 \text { inches, } \\
\text { " } & \text { " } & 8 & \text { " } & \text { " } & 12.2-10.4=1.8 \text { inches, }
\end{array}
$$

and similarly for other classes.

If this increment which is correlated with diameter is deducted from each of the 296 sample trees of the basic data, the residual increment of each tree will be obtained, and these residual increments may be tabulated into a frequency table showing the distribution of uncorrelated increments whose mean will equal 10.4 , the constant subtrahend used in calculating the correlated values.

It is evident therefore, that the gross increment for the period consists of one part which is dependent on the original diameter of the individual trees of the stand at time of release, and another part which is open to random variation according to the distribution of residual increments. It will be shown later how these two divisions of increment may be utilized in arriving at the final stem distribution of a released stand.

The correlated increments and the distributions of residual increment were determined at ages $20,40,60,80$ and 100 years after release. The amounts correlated with diameter for 60.120 years after release were practically identical but for 40 and 20 year periods the amounts were progressively smaller. The correlated increments, however, are dependent on the mean gross increment, rather than on age, and since the mean gross increment for the periods of 60-120 years amounts 6.7-11.4 inches it follows that the correlated increments for mean gross increments between the limits stated are constant. For mean gross increments below 6.7 inches the amount of correlated increment varies as shown in Figure 5 wherein the values have been harmonized for even inch gross increment classes.

When the distributions of residual increment are expressed in per cent. and plotted cumulatively on probability cross-section paper, a straight line through the points fits the data exceptionally well, indicating that the residual distributions may be considered as normal within practical limits of their range ${ }^{3}$. Knowing the mean of residual increment and the standard deviation corresponding to the mean, it follows that the distribution corresponding to any combination of the mean and standard deviation may be readily determined from normal probability tables, with an acceptable degree of accuracy.

3The normality of the residual distributions is shown in appendix $i$. 


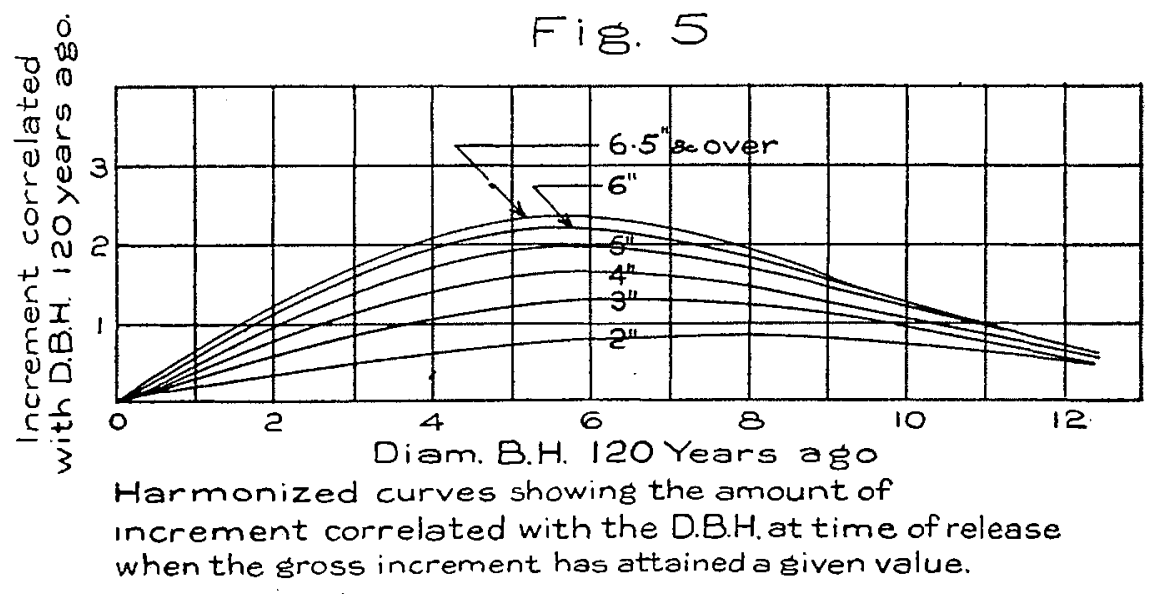

\section{Increment in Cut over Stands Since Cutting}

The increment in the cut-over stands for a period of 15 years following cutting shows the same characteristics, a small amount of the gross increment being dependent on diameter at the time of cutting, and a relatively large amount remaining open to wide variation.

Release of the understory in logging, however, is probably more thorough than it was in the mature stands from natural thinning, and for this reason some differences may be expected in the increment values of the two types for equal periods of time. If these differences can be determined for the 15 year period for which increment data relative to the cut-over type is available, and if similar differences can be expected to apply in the future; then from the data of increment in the uncut stands it will be possible to derive probable increment of the cut-over stands at future periods of time.

The different factors which enter into the determination of increment in the virgin stands for any period are:

1. The mean of gross increment.

2. The amount of increment correlated with the original diameter of the trees.

3. The mean of residual increment.

4. The standard deviation of residual increment.

It is therefore necessary to determine these factors for the cut-over stand over the 15 -year period for which data is available and compare them with the same factors for a similar period following release in the mature stand. 
1. The Mean of Gross Increment:-For the 15 year period since cutting the gross increment in the cut-over stand has amounted to 2.3 inches which is equivalent to $3.1^{4}$ inches in 20 years. The gross increment in the mature stand for 20 years immediately following thinning amounts to 2.0 inches. It is evident then that the increment in the cut-over stands is considerably greater than it was in the mature stands.

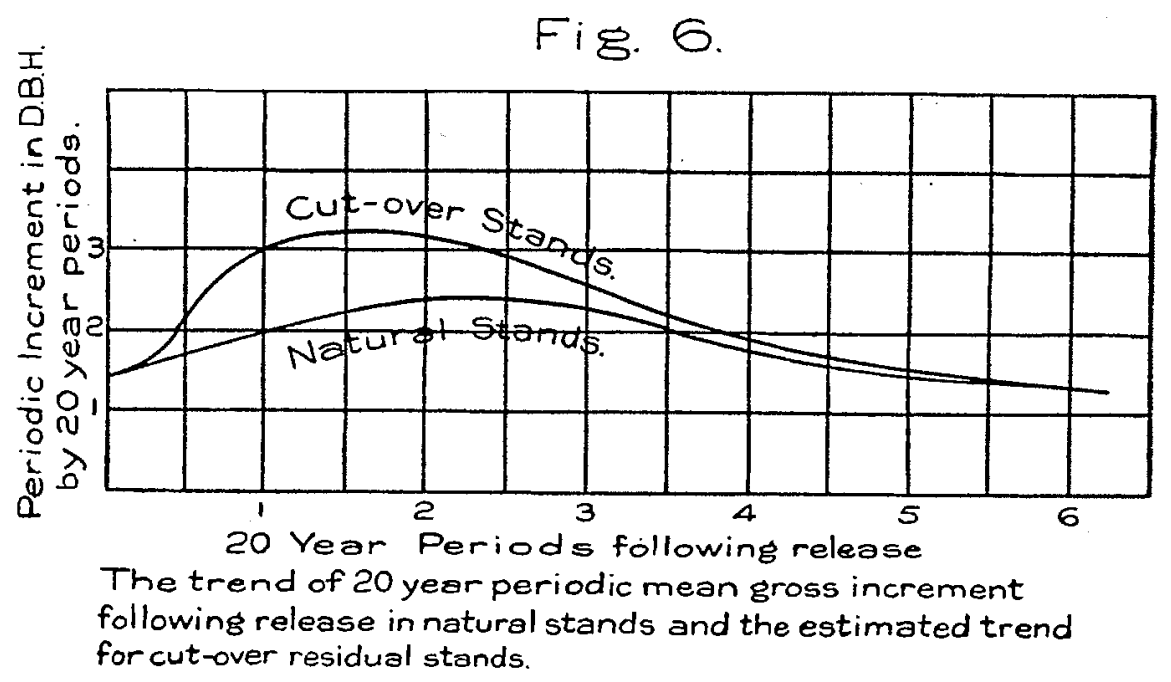

In the mature stands the periodic increment increased for the first $\mathbf{4 0}$ years after thinning and then continually decreased for the next 80 years as indicated by the lower curve of Figure 6 . The increment in the cutover stands however may reach a maximum earlier and begin to fall off earlier, due to the fact that in the cut-over stands release was effected abruptly over a comparatively short period of a year; while in the mature stands release was probably effected much more slowly, perhaps over a period of 20 or even 40 years. It is therefore difficult to determine the future trend of periodic increment in the cut-over stands by comparison with the trend in the mature stands.

In order to arrive at an acceptable indication of the probable trend of increment in cut-over stands, the average gross periodic increments were calculated for trees of the virgin stand which had attained an increment of 2.5 inches or more at 20 years after release. The average gross increment of these trees for the first 20 -year period amounted to 3.1 inches, the

4 Calculated by proportion as follows: $\frac{2.3}{15} \times 20=3.1$ inches. 
same as the average for the cut-over type, and it seems logical to assume that subsequent periodic increments in the cut-over stand will follow the same trend in the future as indicated by the periodic increment curve of these 84 faster growing trees which is shown by the upper curve of Figure 6 .

When the periodic values of this curve are summed cumulatively, and plotted over time since release, the curve of Figure 7 is derived, which shows the average gross increment to be expected in a cut-over stand at any time after release.

$$
\text { Fig. } 2
$$

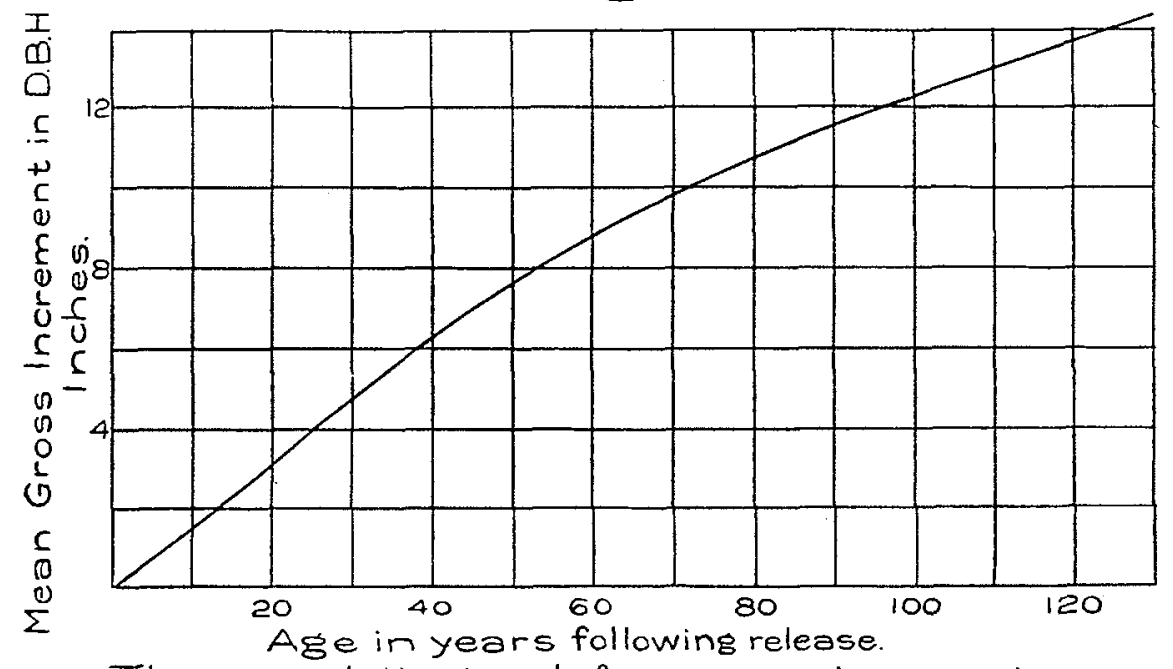

The cumulative trend of mean sross increment with time subsequent to release.

2. The Amount of Increment Correlated with Original Diameter:- The mean gross increment of the cut-over stands over the 15 -year period since cutting amounted to 2.3 inches and a similar curvilinear tendency was evident between a part of this gross and the original tree diameter, to that shown for the released virgin stands. When correlated increment values for a gross increment of 2.3 inches, as interpolated from Figure 5, were subtracted from the gross increment of the individual trees of the cutover stand, and the residuals averaged by original diameter classes were plotted, a horizontal straight line was found to fit the plotted averages reasonably well as shown in Figure 8 . This indicates that when the mean gross increments are the same the amount of increment dependent on diameter is the same in both the released cut-over stand and the naturally released mature stand. 


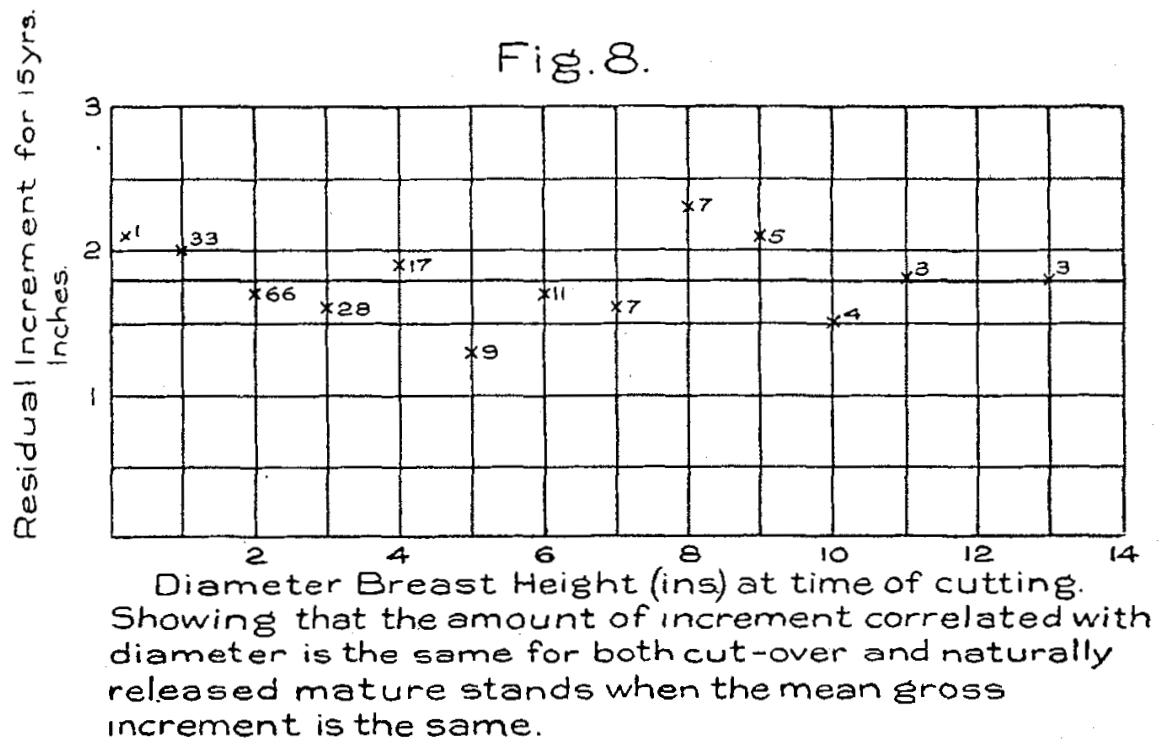

3. The Mean of Residual Increment:-If the trees of the cut-over stand are tabulated in the form of a stand table, i.e. in diameter classes, the total correlated increment for each diameter class may be obtained by multiplying the correlated increment value for each diameter class by the number of trees in the class. The sum of these diameter totals divided by the total number of trees will give the mean correlated increment added, per tree. The gross increment for the period, minus this mean correlated increment, will give the mean residual increment for the stand in question. The mean of residual increment is required in determining the probability of random variation around the mean.

4. The Standard Deviation of Residual Increment:-The distribution of residual increment for the 15 -year period since logging was determined in the cut-over stand by subtracting from the gross increment of each sample tree the amount correlated with diameter. This is the same procedure as followed in determining the distribution of random increment in the virgin stands. This distribution also proved to be practically normal.

Figure 9 shows the standard deviation of residual increment in the virgin stands plotted over the mean of the distribution at $20,40 \ldots 120$ years after release. The standard deviation of random increment for the 15-year period since logging in the cut-over stands amounted to \pm .82 inches for a mean of 2.10 inches. The standard deviation for the same mean in the uncut stands as read from the curve of Figure 9 amounts to \pm 1.00 
inches, from which it is evident that some difference exists between the distributions of the two types. Although this difference is present in the cut-over distribution for the first 15 years since cutting it seems logical to expect that as the cut-over stand approaches complete stocking, the standard deviation of periodic increments will approach the standard deviation of periodic increments of the uncut stand. For instance, the standard deviation for a 2 inch mean residual increment in the virgin stand at the present time (maturity) amounts to \pm .92 inches, and when the cut-over stand reaches maturity the same standard deviation may be expected for the same 2 inch increment. The standard deviation of a 2 inch mean increment in the cut-over stand at present amounts to $\pm .78^{\circ}$ inches and at maturity it may be expected to reach a value of \pm .92 inches. The trend of the standard deviation in the cutover stand for total mean residual increments corresponding to periods of time since logging, may be worked out by summing the standard deviations of the successive 2 inch mean residual increments. The process of this summation is of a technical statistical nature and is outlined in appendix iii. The curve derived from the summation is shown in Figure 9, and from this may be estimated the standard deviation of residual increment corresponding to a mean residual increment realized over any period of time.

In the preceding paragraphs it has been shown in what manner each of the 4 characteristics in cut-over stands, may be expected to vary from measured results in the uncut type. The expected trend of the characteristics for cut-over stands have been presented graphically, and from these charts the values may be estimated for any period of time after cutting has released the residual stand. An example will now be given to show in a more concrete form how the stem distribution of a known cut-over residual stand, may be determined at a given period after cutting.

5. Determination of Stem Distribution of Residual Trees, of 0.6 Inches. and over, at 120 Years After Cutting:-If the trees of the residual cut-over stand are expressed by diameter classes in per cent. of the total number, instead of in actual numbers of trees per acre as in Figure 3, a cumulative percentage stand table can be constructed by summing these percentage values consecutively from the largest diameter class represented to the low. est. This operation is shown in Table 3 for the stem distribution of the clay soil type. The second column of this table states the actual number of trees per acre as read from the curve of Figure 3. The third column states the percentage of the total number of trees in each diameter class,

sCalculated as follows:-for 2.10 in. $= \pm .82$ in.

$$
\text { for } 2.00 \mathrm{in.}= \pm \frac{(.82 \times 2.00)}{2.10}= \pm .78 \mathrm{in}
$$


Fig. 9.

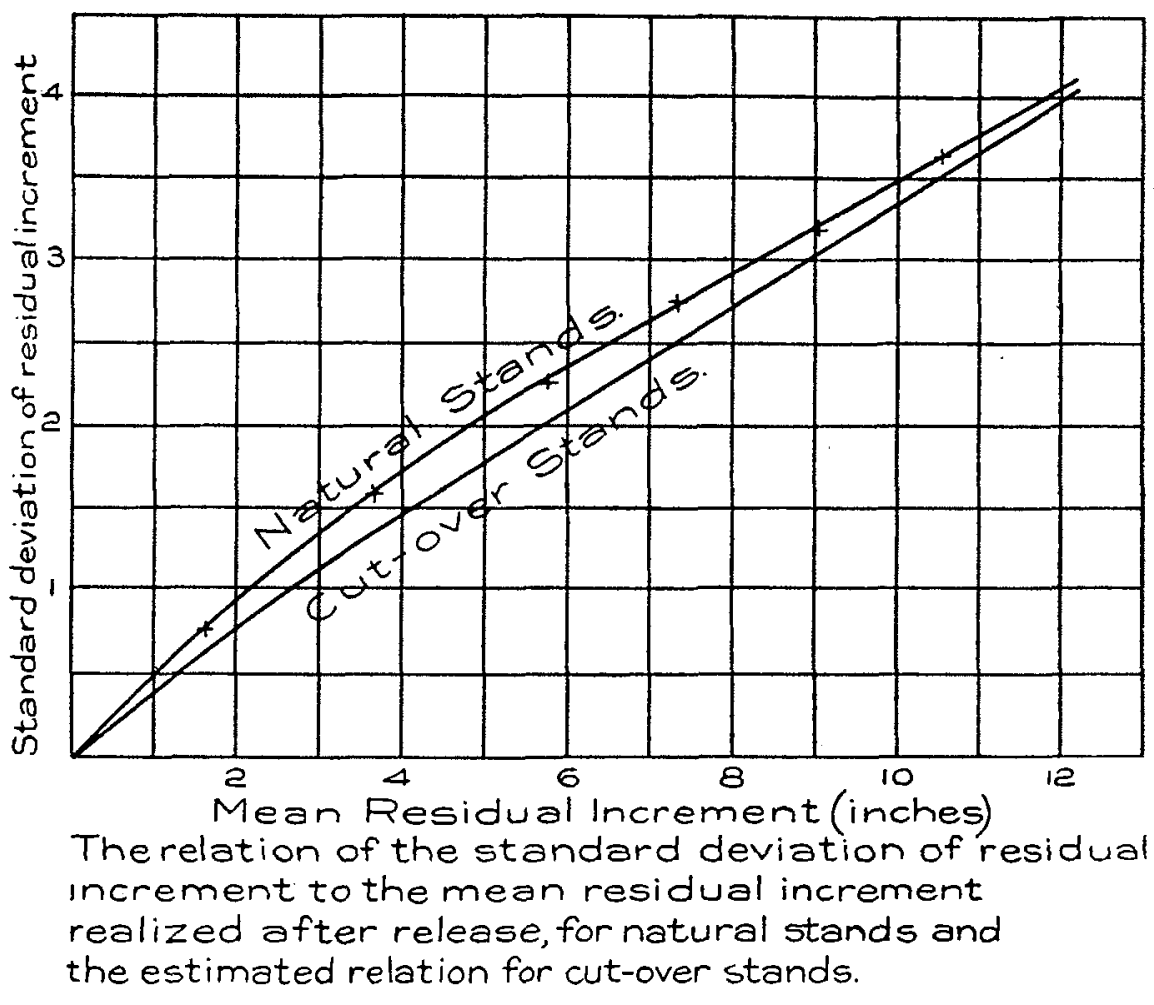

and the fourth is the sum of the successive values of column 3 , starting with the highest diameter class and summing down to the lowest. Each entry of the fourth column shows the percentage of the total number of trees occurring above the lower limit of each diameter class. For example, the first entry of the column indicates that 100 per cent. of the trees lie above 0.6 inches, the lower limit of the 1 inch diameter class. Similarly in turn 72.5 per cent. lie above 1.6 inches, and 1.1 per cent. above 11.6 inches. The lower limits of each diameter class are given in the fifth column.

The cumulative percentage tables thus derived for both the clay and loam soil types are shown graphically in Figure 10, and from these curves the diameters of representative trees of the residual stand may be read for each type. For example, by following along the curve representing the clay soil type it is seen that the largest tree lies above 11.6 inches, the second largest between 11.6 and 10.9, the third between 10.9 and 10.2, and the 100th between 0.6 and 0.5 inches. The diameter of the largest tree will 
then be about 12.0 inches, and of each successive tree, the mean of the intervals between which it falls, i.e., 11.2, 10.5 and the 100th 0.55 inches. By following the entire curve in this manner 100 representative stand diameters may be determined. If retallied by diameter classes the same distribution would be obtained as in the third column of table 3, the original stem distribution on which the curve is based.

Fig. 10 .

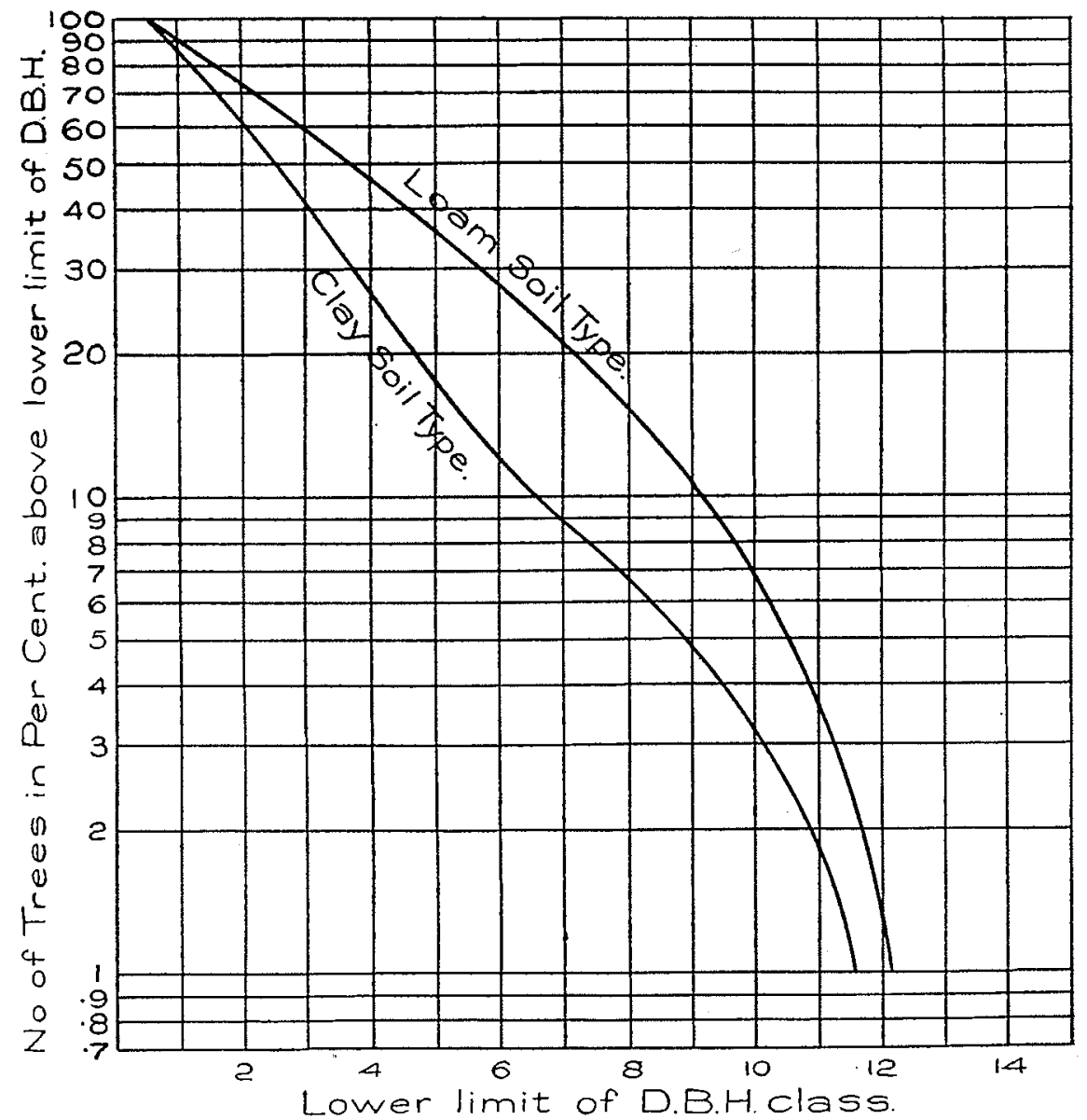

Graphical presentation of the cumulative stand tables of Spruce of the cut-over stands of the clay and loam soil types. 
TABLE 3.

Conversion of Stand Table in Actual Number of Trees per Acre to a Cumulative Stand Table in Per Cent.

Clay soil type cut-over distribution.

\begin{tabular}{|c|c|c|c|c|}
\hline $\begin{array}{l}\text { D.B.H. } \\
\text { Class }\end{array}$ & $\begin{array}{r}\text { No. of S } \\
\text { Actual }\end{array}$ & $\begin{array}{l}\text { uce Trees } \\
\text { Per Cent. } \\
\text { in Class }\end{array}$ & $\begin{array}{l}\text { Acre } \\
\text { Per Cent. } \\
\text { Cumulative }\end{array}$ & $\begin{array}{l}\text { Lower } \\
\text { Limit } \\
\text { D.B.H. } \\
\text { Class }\end{array}$ \\
\hline 1 & 36.0 & 27.5 & 100.0 & 0.6 \\
\hline 2 & 30.0 & 22.9 & 72.5 & 1.6 \\
\hline 3 & 22.0 & 16.8 & 49.6 & 2.6 \\
\hline 4 & 15.0 & 11.5 & 32.8 & 3.6 \\
\hline 5 & 9.1 & 7.0 & 21.3 & 4.6 \\
\hline 6 & 5.2 & 4.0 & 14.3 & 5.6 \\
\hline 7 & 3.2 & 2.5 & 10.3 & 6.6 \\
\hline 8 & 2.6 & 2.0 & 7.8 & 7.6 \\
\hline 9 & 2.3 & 1.8 & 5.8 & 8.6 \\
\hline 10 & 2.0 & 1.5 & 4.0 & 9.6 \\
\hline 11 & 1.8 & 1.4 & 2.5 & 10.6 \\
\hline 12 & 1.5 & 1.1 & 1.1 & 11.6 \\
\hline Sum & 130.7 & 100.0 & - & - \\
\hline
\end{tabular}

The mean gross increment 120 years after release amounts to 13.6 inches (Figure 7). The mean of the correlated increments added to the original diameters amounts to 1.4 inches. $^{8}$ The mean residual increment therefore equals 12.2 inches.

The standard deviation of residual increment corresponding to a mean of 12.2 inches is \pm 4.0 inches, (Figure 9) and the distribution of residual increment having a mean and standard deviation equal to these values is readily determined from normal probability tables.

The sums of the individual tree diameters and correlated increments are now tallied into classes, and the distribution resulting, together with the distribution of residual increment determined from probability tables, is tabulated in Table 4. For convenience in tabulating the following symbols are used-

$$
\begin{aligned}
& D_{o}=\text { Original tree diameter at time of cutting. } \\
& I_{d}=\text { The increment correlated with original diameter of the tree, } \\
& \text { for the period under consideration. } \\
& I_{x}=\text { Residual increment for the period under consideration. } \\
&\left(D_{o}+I_{d}\right)=\text { The sum of the original tree diameter and the increment } \\
& \text { correlated with it for the period under consideration. }
\end{aligned}
$$

GFrom the upper curve of Figure 5 average of the correlated increments of the 100 trees. 
TABLE 4

Distribution in Spruce of $\left(D_{0}+I_{d}\right)$ of Clay Soil Type, and of Ir for a period of 120 Years After Cutting.

\begin{tabular}{|c|c|c|c|}
\hline \multicolumn{2}{|c|}{ Distribution of $\left(D_{o}+1_{d}\right)$} & \multicolumn{2}{|c|}{$\stackrel{2}{2}$ Distribution of $I_{r}$} \\
\hline $\begin{array}{l}\text { Classes } \\
\text { (in.) }\end{array}$ & $\begin{array}{l}\text { Frequency } \\
\text { (per 100) }\end{array}$ & $\begin{array}{l}\text { Classes } \\
\text { (in.) }\end{array}$ & $\begin{array}{l}\text { Frequency } \\
\text { (per 100) }\end{array}$ \\
\hline 1 & 21 & 3 & 2 \\
\hline 3 & 31 & 5 & 4 \\
\hline 5 & 20 & 7 & 7 \\
\hline 7 & 15 & 9 & 16 \\
\hline 9 & 7 & 11 & 19 \\
\hline 11 & 4 & 13 & 19 \\
\hline \multirow[t]{4}{*}{13} & 2 & 15 & 16 \\
\hline & & 17 & .10 \\
\hline & & 19 & 4 \\
\hline & & 21 & 3 \\
\hline Sum & 100 & - & 100 \\
\hline
\end{tabular}

The second distribution states the chances each tree represented in the first distribution has of growing a given amount. The second distribution is a movable table applicable in turn to each diameter class in the first distribution. Thus $2 \%$ of the 21 trees in the 1 inch class of the first distribution will add 3 inches of increment, $4 \%-5$ inches, $7 \%-7$ inches, and so on. Similarly $2 \%$ of the 31 trees in the 3 inch class will add 3 inches, $4 \%-5$ inches, and $7 \%-7$ inches. Multiplying through by the percentage values as recorded gives-

$2 \%$ of $21-1$ inch trees $=.42$ trees will grow 3 inches $=.44-4$ inch trees, $4 \%$ of $21-1$ inch trees $=.84$ trees will grow 5 inches $=.84-6$ inch trees, $7 \%$ of $21-1$ inch trees $=1.47$ trees will grow 7 inches $=1.47-8$ inch trees. Similarly:

$2 \%$ of $31-3$ inch trees $=.62$ trees will grow 3 inches $=.62-6$ inch trees. $4 \%$ of $31-3$ inch trees $=1.24-8$ inch trees.

Completing this process for all combinations of the two distributions and summing all trees of the same final diameter classes gives the final stem distribution of the cut-over stand at 120 years after cutting in per cent. Table 5 shows the systematic computations of the operation described above and the stem distribution derived from it. 


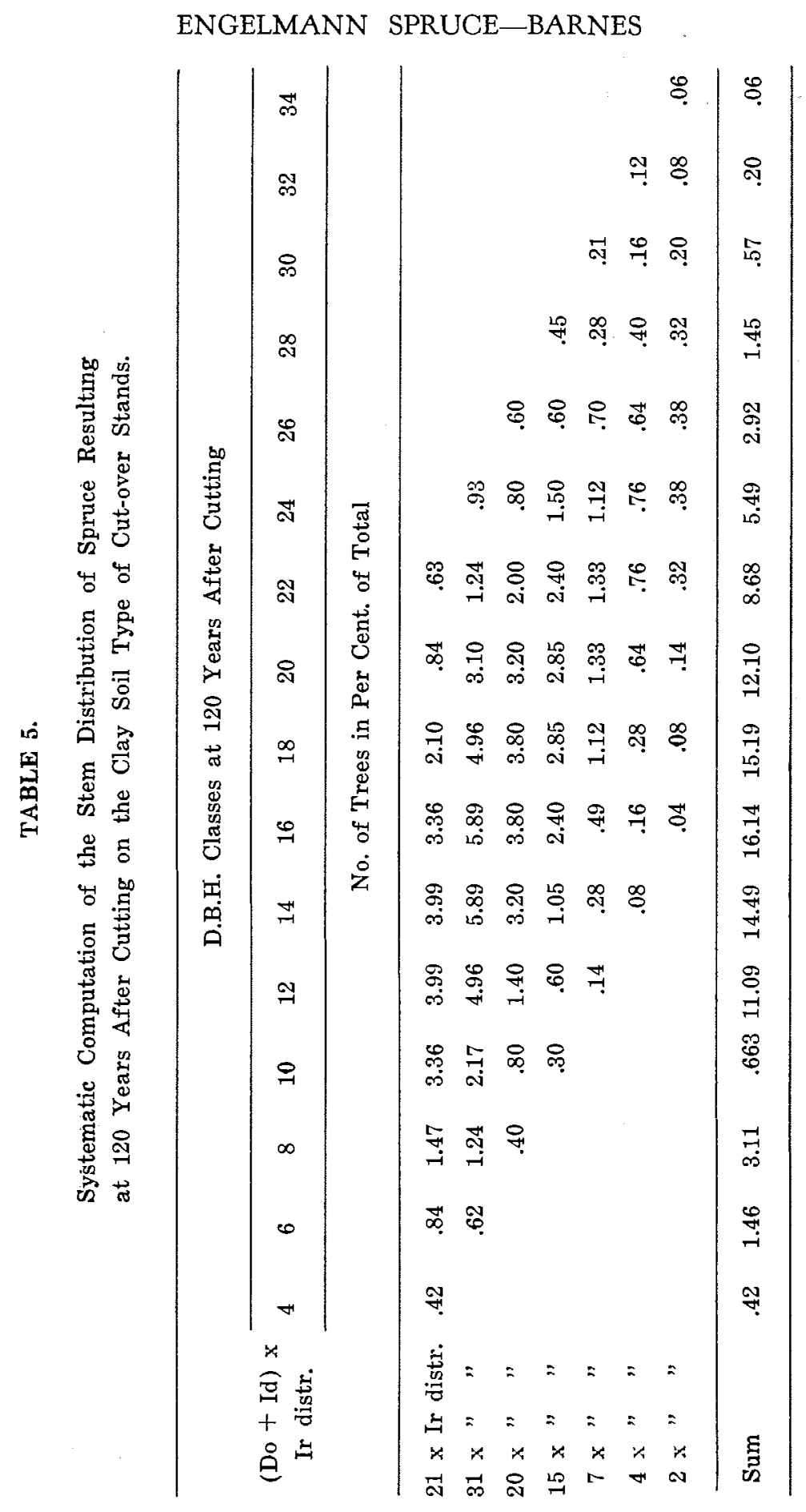


The stem distributions were computed in a similar manner for both the clay type and loam type cut-over stands at periods of 40,60,80,100 and 120 years after logging. The essential statistics required for the computations are shown in Table 6 , and the final distributions derived, in Table 7.

TABLE 6

Essential Statistics Required in Determining the Stem Distribution of Spruce of the Residual Stand of the Clay and Loam Soil Types at Given Intervals Subsequent to Logging.

\begin{tabular}{lrrrrrrrrrrr}
\hline \multicolumn{1}{c}{} & \multicolumn{4}{c}{ Clay Type } & \multicolumn{4}{c}{ Loam Type } \\
& 40 & 60 & 80 & 100 & 120 & 40 & 60 & 80 & 100 & 120 \\
\hline Mean Gross Incr. $\ldots \ldots \ldots \ldots$ & 6.2 & 8.7 & 10.6 & 12.2 & 13.6 & 6.2 & 8.7 & 10.6 & 12.2 & 13.6 \\
Mean Correlated Incr. $\ldots \ldots$ & 1.2 & 1.4 & 1.4 & 1.4 & 1.4 & 1.4 & 1.5 & 1.5 & 1.5 & 1.5 \\
Mean Residual Incr. (Ir) $\ldots$ & 5.0 & 7.3 & 9.2 & 10.8 & 12.2 & 4.8 & 7.2 & 9.1 & 10.7 & 12.1 \\
Standard Dev'n. of Ir Ir . . . . & 1.8 & 2.5 & 3.2 & 3.6 & 4.0 & 1.7 & 2.5 & 3.1 & 3.5 & 4.0 \\
\hline
\end{tabular}

TABLE 7.

Distribution of Spruce Trees of Residual Stands by Diameter Classes on Clay and Loam Soil Types at Given Intervals Subsequent to Logging. (Stated as Per Cent. of Total Number).

\begin{tabular}{|c|c|c|c|c|c|c|c|c|c|c|}
\hline \multirow{3}{*}{$\begin{array}{c}\text { D.B.H. } \\
\text { Class } \\
\text { (in.) }\end{array}$} & \multicolumn{5}{|c|}{ Clay Type } & \multicolumn{5}{|c|}{ Loam Type } \\
\hline & s 40 & 60 & 80 & 100 & 120 & 40 & 60 & 80 & 100 & 120 \\
\hline & \multicolumn{10}{|c|}{ Number of Trees as Per Cent. of Total Number } \\
\hline 2 & .9 & & & & & .7 & & & & \\
\hline 4 & 6.5 & 1.8 & .8 & .6 & .4 & 5.1 & 1.5 & .9 & .4 & .2 \\
\hline 6 & 18.3 & 6.8 & 4.4 & 2.2 & 1.5 & 14.0 & 5.0 & 2.5 & 1.5 & 1.0 \\
\hline 8 & 25.2 & 15.1 & 9.7 & 5.1 & 3.1 & 18.6 & 11.2 & 6.1 & 3.7 & 2.5 \\
\hline 10 & 21.1 & 21.0 & 15.8 & 9.7 & 6.6 & 18.1 & 16.0 & 11.1 & 7.4 & 5.2 \\
\hline 12 & 13.3 & 20.3 & 18.8 & 14.5 & 11.1 & 16.4 & 17.7 & 14.9 & 11.5 & 8.6 \\
\hline 14 & 7.6 & 15.4 & 17.8 & 16.8 & 14.5 & 13.8 & 16.6 & 16.5 & 14.7 & 12.1 \\
\hline 16 & 4.4 & 9.7 & 14.0 & 16.6 & 16.1 & 8.9 & 14.0 & 15.8 & 15.7 & 14.3 \\
\hline 18 & 2.1 & 5.6 & 9.0 & 13.4 & 15.2 & 3.6 & 9.9 & 13.2 & 15.0 & 15.0 \\
\hline 20 & .6 & 2.8 & 5.3 & 9.9 & 12.1 & .8 & 5.4 & 9.5 & 12.3 & 13.5 \\
\hline 22 & & 1.1 & 2.8 & 5.9 & 8.7 & & 2.1 & 5.6 & 8.7 & 11.1 \\
\hline 24 & & .4 & 1.2 & 3.2 & 5.5 & & .5 & 2.7 & 5.3 & 7.8 \\
\hline 26 & & & .4 & 1.5 & 2.9 & & .1 & 1.0 & 2.6 & 4.8 \\
\hline 28 & & & & .6 & 1.4 & & & .2 & 1.0 & 2.5 \\
\hline 30 & & & . & & .6 & & & & .2 & 1.1 \\
\hline 32 & & & & & .3 & & & & & .3 \\
\hline Sum & 100.0 & 100.0 & 100.0 & 100.0 & 100.0 & 100.0 & 100.0 & 100.0 & 100.0 & 100.0 \\
\hline
\end{tabular}


MORTALITY

The mortality records for both the mature and the cut-over stands cover such a short span of time that the values derived from them may be considered only as rough approximations.

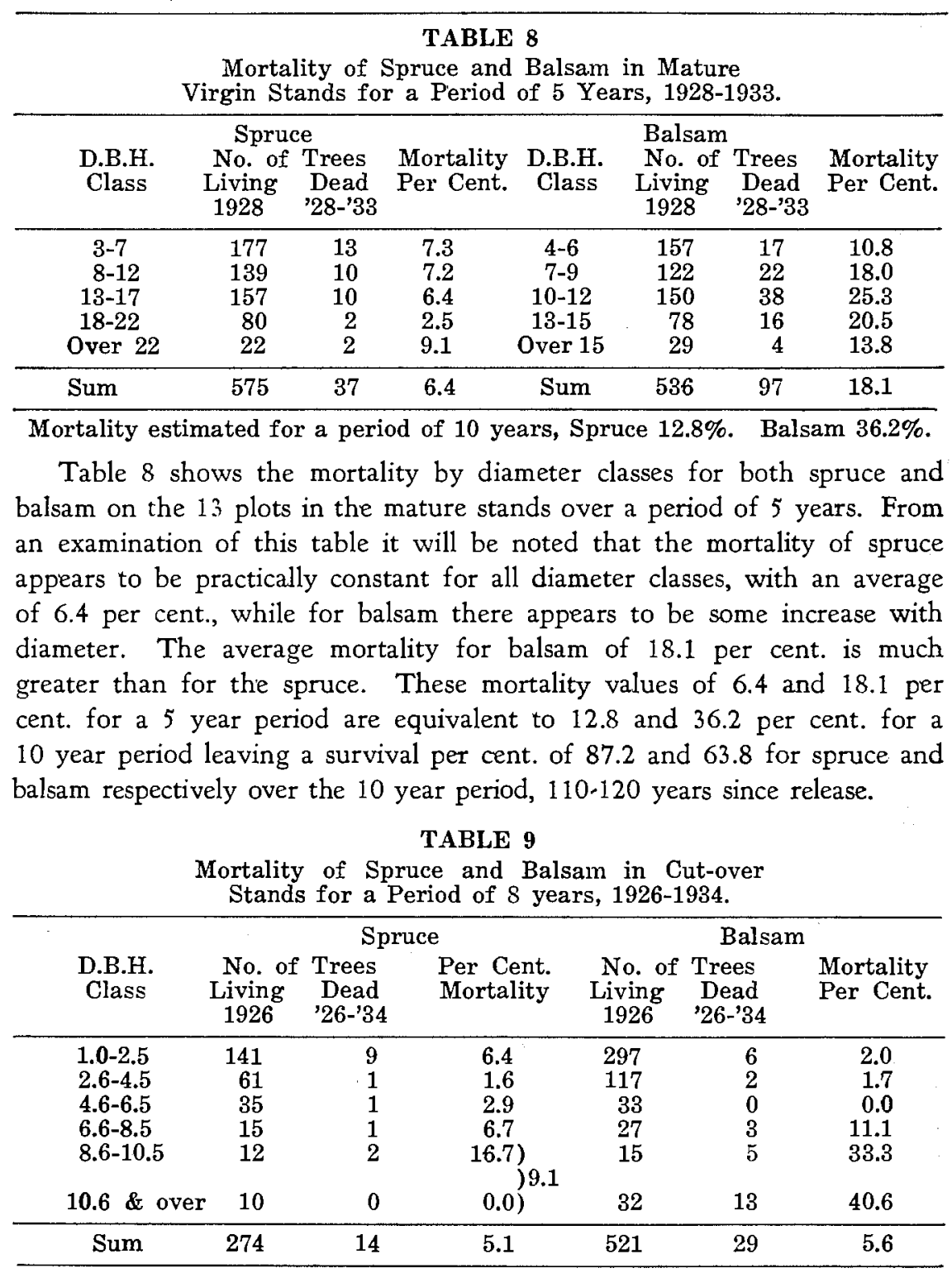

Mortality estimated for a period of 10 years, Spruce $6.4 \%$. Balsam $7.0 \%$. 
Table 9 shows the mortality of spruce and balsam in the residual immature stands on cut over land for a period of 8 years. It is apparent here also that the mortality of spruce is practically constant with diameter.

For balsam, again, there appears to be an increase in mortality with diameter. The average mortality of spruce for the 8 year period amounts to 5.1 per cent. and for balsam 5.6 per cent. For a 10 year period these values are equal to 6.4 and 7.0 per cent. respectively, leaving a survival per cent. of 93.6 and 93.0 for the 10 year period, immediately following release.

\section{SURVIVAL EXPECTANCY OF SPRUCE}

The naturally released mature stands have reached their present mature condition in approximately 120 years after release occurred, so it may be expected that the cut-over stands will also reach maturity in about the same period. It may therefore be expected that the present 10 year periodic survival per cent. of 93.6 will constantly decrease to a value of 87.2 per cent. in the twelfth decade. If the difference is equally distributed over the 12 decades, period survival percentages may be calculated which are shown in Table 10.

TABLE 10

Periodic Survival Percentages for Successive Decades Following Release.

\begin{tabular}{cccc}
\hline $\begin{array}{c}\text { Decade } \\
\text { After } \\
\text { Release }\end{array}$ & $\begin{array}{c}\text { Periodic } \\
\text { Survival } \\
\text { Per Cent. }\end{array}$ & $\begin{array}{c}\text { Decade } \\
\text { After } \\
\text { Release }\end{array}$ & $\begin{array}{c}\text { Periodic } \\
\text { Survival } \\
\text { Per Cent. }\end{array}$ \\
\hline 0 & 100 & 7 & 90.1 \\
1 & 93.6 & 8 & 89.5 \\
2 & 93.0 & 9 & 89.0 \\
3 & 92.3 & 10 & 88.3 \\
4 & 91.8 & 11 & 87.8 \\
5 & 91.3 & 12 & 87.2 \\
6 & 90.7 & & \\
\hline
\end{tabular}

From these periodic values, the survival percentage for a complete period of time after cutting may be calculated. For instance, at 10 years after cutting the survival per cent. is,

$$
\begin{array}{lr}
93.6 \times 1= & 93.6 \text { per cent. } \\
\text { at } 20 \text { years, } 93.0 \times 93.6 \times 1= & 87.0 \text { per cent. } \\
\text { at } 30 \text { years, } 92.3 \times 93.0 \times 93.6 \times 1= & 80.3 \text { per cent. } \\
\text { at } 120 \text { years, } 87.2 \times 87.8 \times 88.3- & =1=29.6 \text { per cent. }
\end{array}
$$

The values so calculated are summarized in Table 11 for 20 year age classes after release. 


\section{SURVIVAL EXPECTANCY OF BALSAM}

On the same basis of reasoning the periodic survival per cent. for balsam will reduce from 93.0 in the first decade after cutting to 63.8 at maturity in the twelfth decade. Again, distributing the difference equally over the 12 decades, the survival percentages may be calculated as they were for the spruce for complete periods after cutting. The final values are given in Table 11 together with the values for the spruce.

\section{COMPOSITION OF STANDS MATURING AFTER CUTTING}

In both of the cut-over stands examined there were 130 spruce trees per acre between 0.5 and 12.5 inches in diameter. In Table 11 it is estimated that about 30 per cent. of them will survive in 120 years, leaving 39 . There were 394 balsam on the clay soil type and 351 on the loam type of which only 8 per cent. or 32 and 28 trees respectively will remain at 120 years after cutting. The merchantable trees of the mature stand will consist mainly of these remnants of the original cut-over stand, as few trees entering subsequent to cutting will have attained a merchantable size at this time. It appears therefore that the merchantable stand at maturity will consist of trees about equally divided in number between the two species. The mortality of balsam occurs predominantly among the larger diameter classes, while in spruce it is evenly distributed over the diameter classes. A greater proportion of the surviving spruce will therefore attain maximum diameters than of the balsam. Furthermore, the surviving balsam of the second crop is likely to be just as heavily infected with heart rot as the mature stand of to-day. It is thus evident that spruce is likely to far outweigh the balsam by net merchantable volume in the second crop.

The number of original trees of over 0.5 inches in diameter present in the cut-over stands, expected to survive at different ages after cutting are shown in Table 11.

TABLE 11

Survival Expectancy of Spruce and Balsam Cut-over Stands at Given Periods After Cutting.

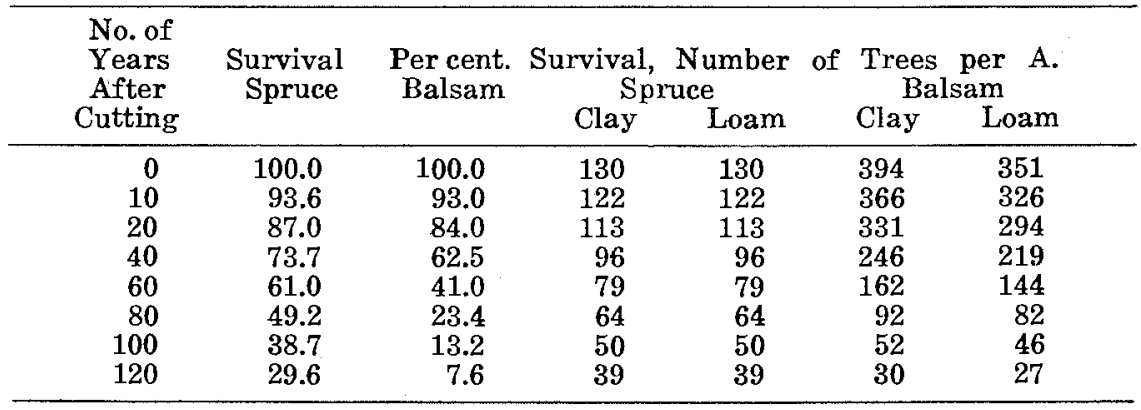




\section{NEW TREES ENTERING THE STAND AFTER CUTTING}

So far we have dealt only with increment produced by trees of the residual stand above breast height, that is with trees having a breast height diameter. As the stand develops, additional trees will attain this class through growth and will eventually become an important source of addi. tional increment. These new entrants will consist at first entirely of those trees present at time of cutting but below 4.5 feet in height, and later of individuals germinating subsequent to cutting.

The entry of these additional trees does not seriously effect the final merchantable yield of the cut-over stand as relatively few of them will have attained a merchantable size before a second crop has matured. It does effect the final distribution of the smaller diameter classes in the stand however, and accounts for the bimodal distribution of mature stands which has been previously mentioned.

In making the increment measurements of the mature stand, the breastheight ages of all trees over 4 inches on the plots were incidentally recorded. This made it possible to classify all trees of the virgin stand by diameterage classes, and from this classification it was possible to determine the diameter distribution of the total number of trees entering the stand above a 4 inch minimum diameter over any given period of time subsequent to release.

Table 12 shows the distribution per acre by diameter classes of the total number of trees below given breast-height ages now existing in the mature stands. The last column of the table shows the distribution of trees which have attained a diameter of 4 inches or more over the past 120 years. Since these trees are 120 years or less of age, and since it has been assumed that the stands were released about 120 years ago by a natural thinning, it follows that these same trees were of breast height or less at the time of thinning, and have since attained diameters as tabulated.

TABLE 12

Number of Spruce Trees Under Breast Height at Time of Cutting Entering the Stand 4 Inches and Over at Stated Intervals Subsequent to Cutting, by D.B.H. Classes.

\begin{tabular}{|c|c|c|c|c|c|}
\hline $\begin{array}{l}\text { D.B.H. } \\
\text { Class }\end{array}$ & 40 & $\underset{60}{\text { Number }}$ & $\begin{array}{c}\text { Years } \\
80\end{array}$ & $\begin{array}{c}\text { After } C \\
100\end{array}$ & $\mathrm{~g}_{120}$ \\
\hline $\begin{array}{r}4 \\
6 \\
8 \\
10 \\
12 \\
14 \\
16 \\
18 \\
20\end{array}$ & .5 & $\begin{array}{r}3.2 \\
.8 \\
.1\end{array}$ & $\begin{array}{r}6.0 \\
3.0 \\
.8 \\
.2\end{array}$ & $\begin{array}{r}10.5 \\
6.4 \\
3.0 \\
1.5 \\
.4 \\
.2 \\
\end{array}$ & $\begin{array}{r}16.0 \\
12.0 \\
5.2 \\
3.3 \\
2.0 \\
1.4 \\
1.1 \\
.7 \\
.3\end{array}$ \\
\hline
\end{tabular}


Approximately the same conditions may be expected to exist in the cut-over stands at 120 years after cutting. If this distribution is added to the distribution formed by the growth of trees above breast height at time of cutting a composite distribution is derived of both of them. (See Figure 11).

Fig.ll.

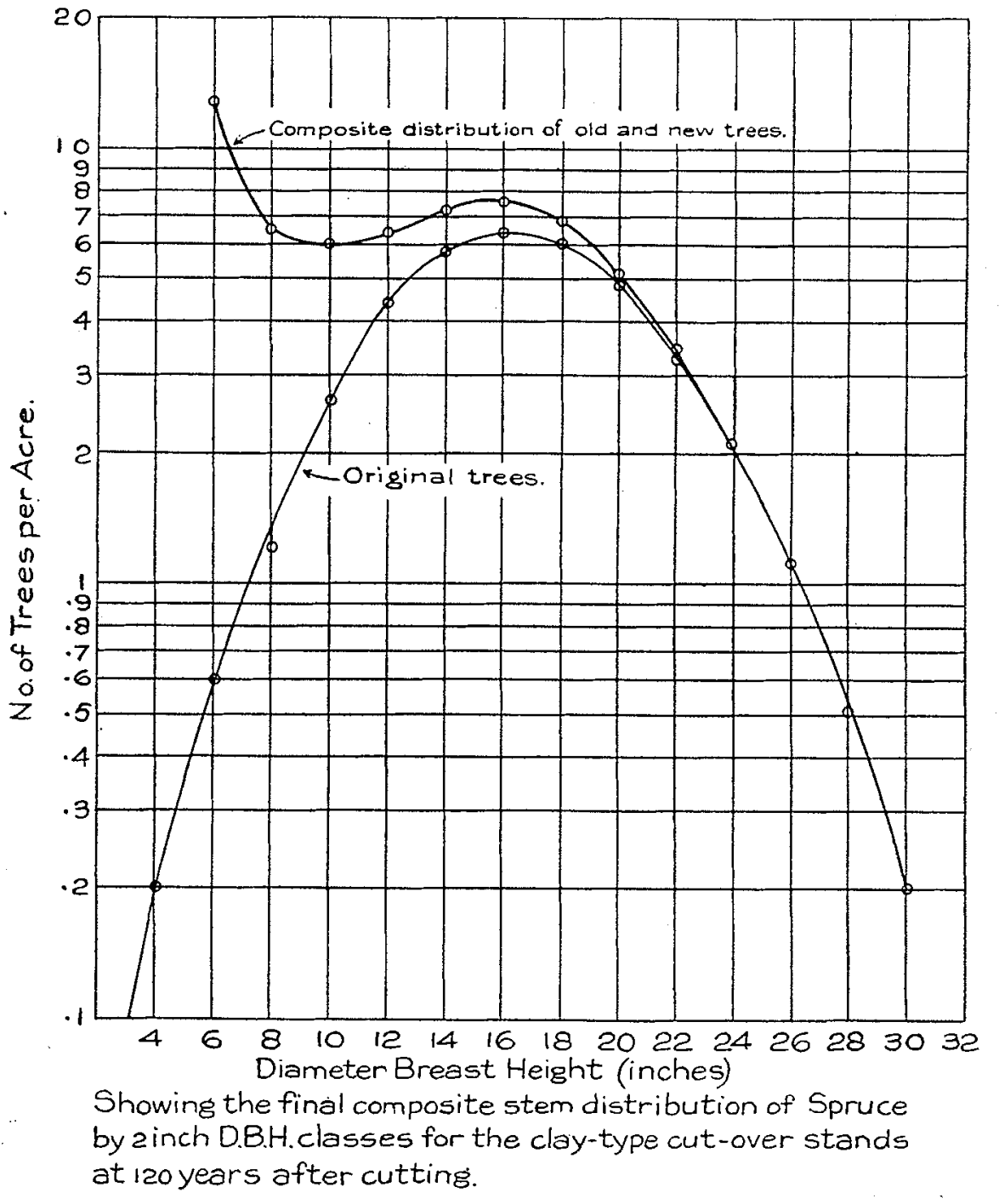


In a like manner the distributions tabulated for the other age classes, represent the diameters attained by trees under breast height at time of release in the past $20,40,60$, and 100 years. They may be regarded as a progression of distributions, each one of which develops into the one immediately above it in a 20 year period. The 40 year distribution develops into the 60 year distribution in the following 20 years, and into the 80 year distribution in the next 20 years. The distributions really represent conditions over the past $40,60, \ldots 120$ years, rather than at the same intervals following release, and although some differences may develop in periods after release as compared with the same periods in the past, similarity will again be assumed in order to illustrate the form of the complete stem distributions at given periods after cutting. Few of these trees will have attained a merchantable size at the time a second crop has matured so that they will not affect the final volume calculations to any great extent. They are of interest only in indicating the form of the final stem distribution.

\section{FINAL STEM DISTRIBUTIONS AND ESTIMATED YIELDS OF SPRUCE}

Of the total number of spruce trees over breast height present in the cutover stand immediately after logging, the number surviving at any one period in the future may be determined from the survival expectancies of Table 11. This number may then be segregated into diameter classes by the percentage values tabulated for diameter classes in Table 7. Thus, from Table 11, it is found that 39 spruce trees will survive at 120 years after cutting; and from Table 7, it is found that, 0.4 per cent. of the 39 trees will be 4 inch trees; 1.5 per cent. 6 inch trees; 3.1 per cent. 8 inch trees; and so on to 0.3 per cent. 32 inch trees.

When the distributions of trees have been so determined for periods of $40,60,80,100$ and 120 years after logging, the distributions of new trees entering the stand over similar periods as tabulated in Table 12 may be added. The sum of the two distributions gives the final stem distribution per acre, and the results are tabulated in Table 13. The composite distributions at 120 years after cutting are shown graphically in Figures 11 and 12 for the clay and loam soil types.

It is interesting to note that at maturity, these distributions have the same bimodal characteristic common to the present mature stands as shown in Figure 2. As previously noted, this is due to the fact that the final distribution is composed of trees already in the stand at time of logging, together with new trees entering after logging. The new trees entering after cutting consist to a small extent of trees under breast height at this time, but mainly of trees germinating subsequent to cutting. 
Fig. 12 .

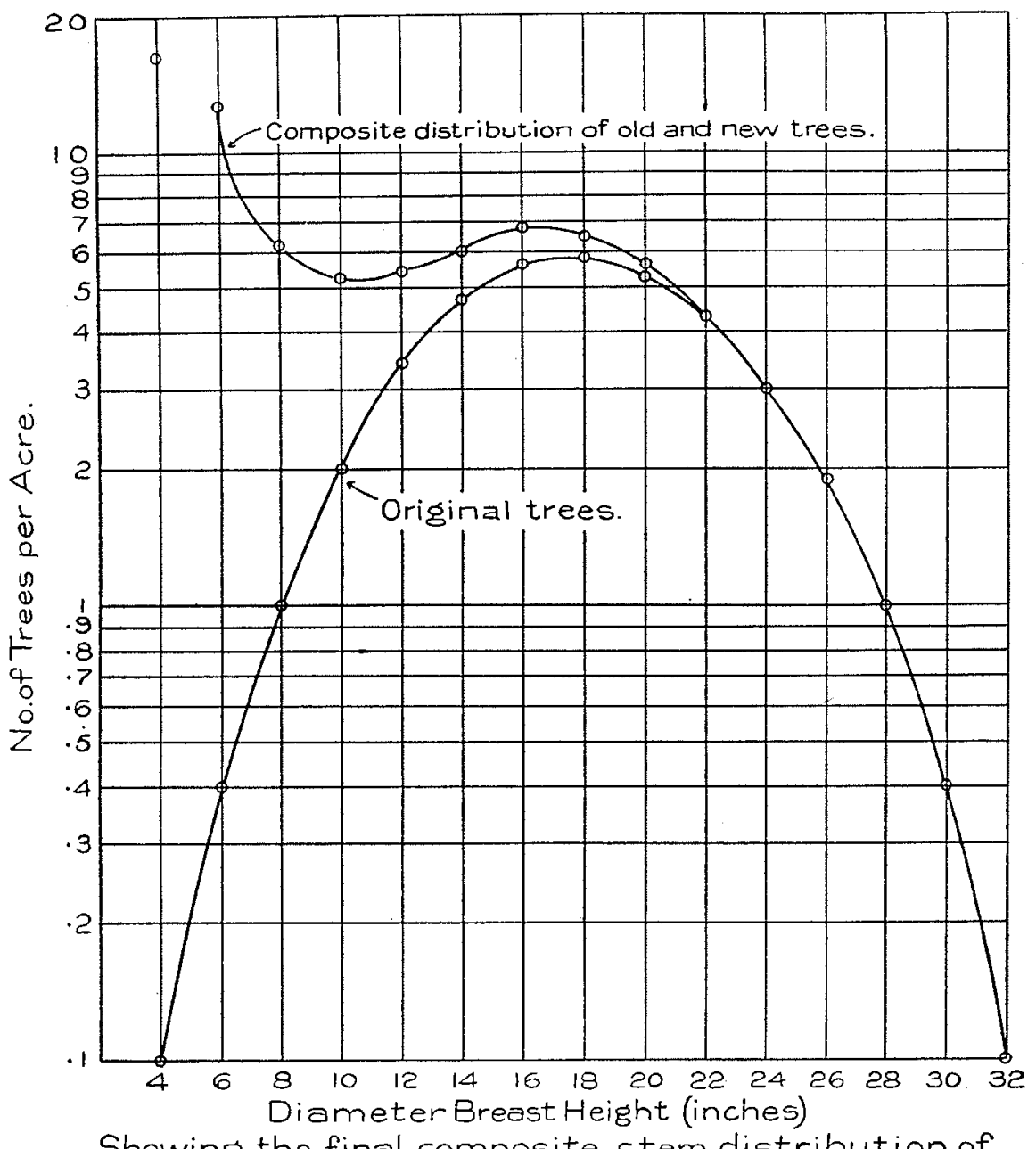

Showing the final composite stem distribution of Spruce by 2 inch D.B.H. classes for the loam-type cut-over stands at 120 years after cutting.

Having obtained the final stem distributions as in Table 13 heights were assigned from a diameter height curve to each diameter class represented. The heights of trees of the same diameter classes were practically the same on both the clay and the loam soil types, so the same height curve was used for both types. By reference to a volume table the total volumes for the different 
ages after cutting are readily computed and are shown in Table 14. The yield in board feet has been computed to a minimum d.b.h. of 11 inches, and in cubic feet to a minimum of 7 inches.

TABLE 13

Composite Stem Distributions of Spruce for Cut-over Stands of the Clay and Loam Soil Types at Given Ages After Cutting.

\begin{tabular}{|c|c|c|c|c|c|c|c|c|c|c|}
\hline \multirow{3}{*}{$\begin{array}{l}\text { D.B.H. } \\
\text { Class }\end{array}$} & & \multicolumn{4}{|c|}{ Clay Type } & \multicolumn{5}{|c|}{ Loam Type } \\
\hline & \multirow[t]{2}{*}{40} & 60 & 80 & 100 & 120 & 40 & 60 & 80 & 100 & 120 \\
\hline & & No. o & Tree & per & & \multicolumn{5}{|c|}{ No. of Trees per Acre } \\
\hline 4 & 6.7 & 4.6 & 6.5 & 10.8 & 16.2 & 5.4 & 4.4 & 6.6 & 10.7 & 16.1 \\
\hline 6 & 17.6 & 6.2 & 5.8 & 7.5 & 12.6 & 13.4 & 4.7 & 4.6 & 7.2 & 12.4 \\
\hline 8 & 24.2 & 12.0 & 7.0 & 5.6 & 6.4 & 17.9 & 8.9 & 4.7 & 4.8 & 6.2 \\
\hline 10 & 20.2 & 16.6 & 10.3 & 6.3 & 5.9 & 17.4 & 12.6 & 7.3 & 5.2 & 5.3 \\
\hline 12 & 12.8 & 16.0 & 12.0 & 7.7 & 6.3 & 15.7 & 14.0 & 9.5 & 6.1 & 5.4 \\
\hline 14 & 7.3 & 12.2 & 11.4 & 8.6 & 7.1 & 13.2 & 13.1 & 10.6 & 7.6 & 6.1 \\
\hline 16 & 4.2 & 7.7 & 9.0 & 8.3 & 7.4 & 8.5 & 11.1 & 10.1 & 7.8 & 6.7 \\
\hline 18 & 2.0 & 4.4 & 5.7 & 6.7 & 6.7 & 3.5 & 7.8 & 8.5 & 7.5 & 6.5 \\
\hline 20 & .6 & 2.2 & 3.4 & 4.9 & 5.0 & .8 & 4.3 & 6.1 & 6.2 & 5.6 \\
\hline 22 & & .9 & 1.8 & 3.0 & 3.4 & & 1.7 & 3.6 & 4.4 & 4.3 \\
\hline 24 & & .3 & .8 & 1.6 & 2.1 & & .4 & 1.7 & 2.6 & 3.0 \\
\hline 26 & & & .3 & .7 & 1.1 & & .1 & .6 & 1.3 & 1.9 \\
\hline 28 & & & & .3 & .5 & & & .1 & .5 & 1.0 \\
\hline 30 & & & & & .2 & & & & .1 & .4 \\
\hline 32 & & & & & .1 & & & & & .1 \\
\hline
\end{tabular}

TABLE 14

Estimated Yields of Spruce in Board Feet and Cubic Feet of Cut-over Stands of the Clay and Loam Soil Types.

\begin{tabular}{|c|c|c|c|c|}
\hline \multirow[b]{2}{*}{ Age } & \multicolumn{2}{|c|}{ Clay Type } & \multicolumn{2}{|c|}{ Loam Type } \\
\hline & B.M. ${ }^{\mathrm{a}}$ & Cu.M.b & B.M. ${ }^{\mathrm{a}}$ & Cu.M.b \\
\hline $\begin{array}{r}40 \\
60 \\
80 \\
100 \\
120\end{array}$ & $\begin{array}{r}4,600 \\
8,500 \\
10,500 \\
11,600 \\
12,400\end{array}$ & $\begin{array}{l}1,600 \\
2,230 \\
2,500 \\
2,650 \\
2,780\end{array}$ & $\begin{array}{r}7,600 \\
11,800 \\
13,800 \\
14,100 \\
14,300\end{array}$ & $\begin{array}{l}2,150 \\
2,900 \\
3,100 \\
3,150 \\
3,150\end{array}$ \\
\hline
\end{tabular}

2-B.M. Volume-By B.C. Log Rule.

b_Cu. ft. Volume-Merchantable Vol. inside bark.

Mortality, being one of the important factors on which ultimate yields are dependent, could be estimated only roughly from the data at hand, and it follows therefore that the final yield values may be considered only as approximations. Throughout the investigation however, wherever a choice was offered, the most conservative policy was always adopted and it is believed that the yields as calculated are more likely to underestimate, than overestimate, actual development. 
In any event, the results indicate that a satisfactory second crop may be matured from residual stands remaining after logging, and that although the original residual stand is predominantly balsam, it will develop into a predomination of spruce at maturity. These are important points in determining the management of the spruce-balsam timber type, and the investigation will have fulfilled its main purpose if it does no more than indicate efficient methods of handling these stands.

\section{RECOMMENDATIONS FOR FURTHER INVESTIGATIONS}

The investigation so far has covered only conditions as they exist at the Aleza Lake Forest. From general observations it has been noticed that two types of mature forest may be recognized in the Upper Fraser district. One, to which the Aleza Lake forest belongs, has developed over a long period of time through successive stages of maturity. One or more generations of mature trees have already given way through decadence to the present generation. This type is probably the more extensive and important one of the two. The other type has developed for only a long enough period to mature the first generation and can be distinguished readily by the remnants of hardwood species under which the coniferous stand has developed. The first type represents the climax forest conditions, while the second is merely a temporary type, which, if untouched by man, will develop in another generation into the climax type.

The climax type usually carries a much heavier understory than the temporaty first generation type and it is to the former that any management system which may develop out of these studies must apply.

Further investigations in regard to practical management problems are recommended' as follows:

1. Methods of brush disposal other than broadcast burning suited to the preservation of the residual stand and to the reduction of fire hazard.

2. Posssibilities of improving the amount of spruce in the final crop of the residual stand by sacrificing inferior species (balsam and birch) which in some cases hinder the development of smaller spruce situated beneath them.

3. Practical methods of baring the mineral soil in openings resulting from skid roads and log decking sites in order to favour the establishment of spruce reproduction thereon.

4. Extension of the investigations to cover a wider range of the type. 


\section{ApPEndix I. \\ SIGNIFICANCE OF THE DIFFERENCE BETWEEN BASAL AREAS \\ OF SAMPLE PLOTS IN 1928 AND 1933}

Table 15 shows the differences in per cent. between the basal areas of the sample plots in 1928 and 1933, using the 1928 basal area as the base. The deviation of each plot difference from the mean difference is also tabulated and the standard deviation of the differences is calculated therefrom.

TABLE 15

Differences in Per cent. of the Sample Plot Basal Areas in 1928 and 1933, and Calculation of the Significance of the Mean Difference.

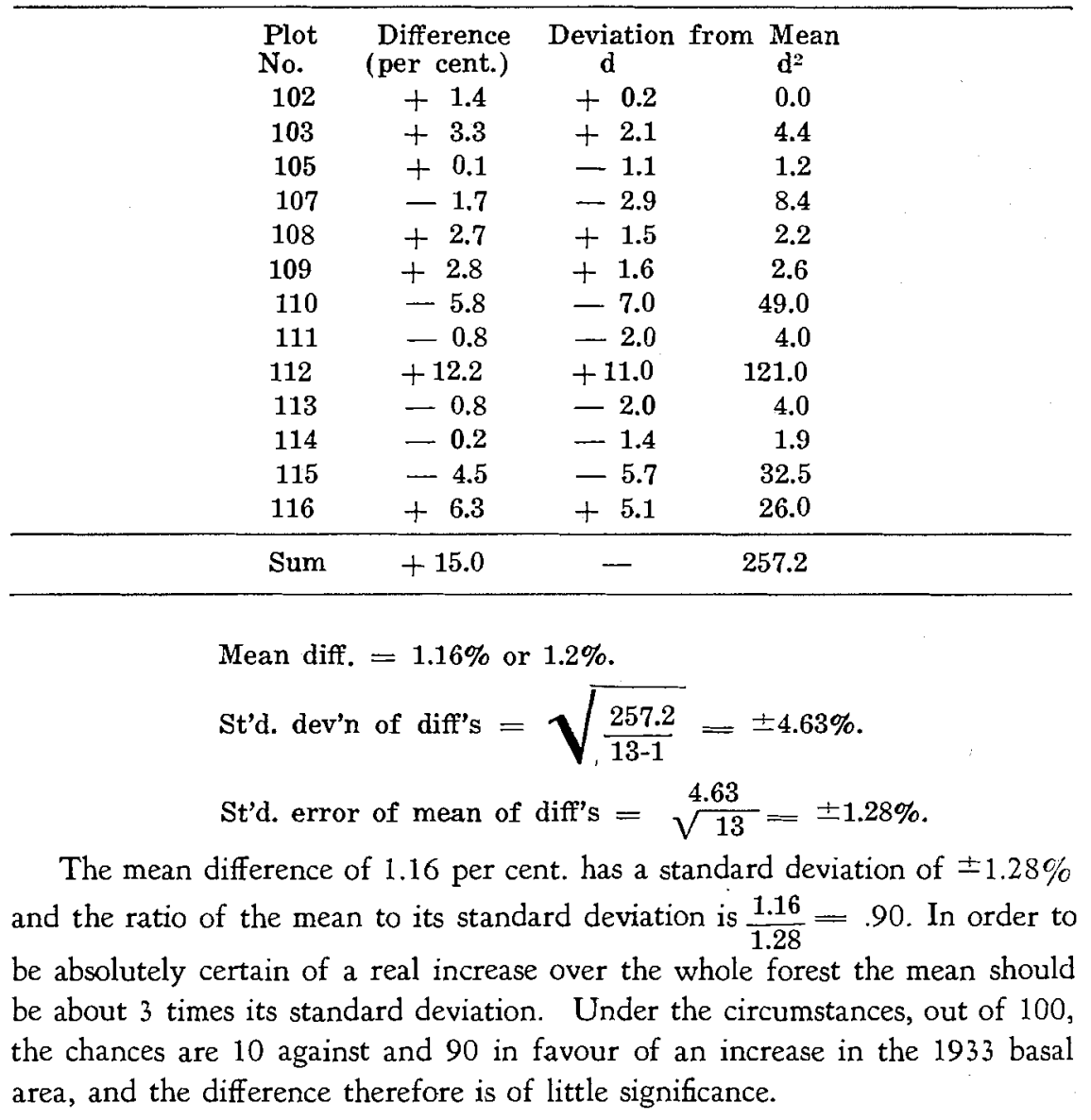


APPENDIX II.

THE NORMALITY OF THE RESIDUAL INCREMENT DISTRIBUTIONS OF SPRUCE

The distributions of residual increment of the mature stand for periods of $20,40,60,80,100$ and 120 years after release were expressed cumulatively starting at the lowest frequency represented in the distribution, and the cumulative values then converted to per cent. of the total frequencies. The cumulative percentage values as shown in Table 16 are plotted on arithmetic probability paper in Figure 13. A straight line fits the plotted points of each distribution exceptionally well above their lowest plotted limit of about 2 per cent. This indicates that the original residual increment distributions may be considered normal above this limit.

TABLE 16

Frequency Distributions of Residual Increment of Spruce in the Mature Stands at Complete Periods Subsequent to Release.

\begin{tabular}{|c|c|c|c|c|c|c|c|c|}
\hline \multicolumn{3}{|c|}{20} & \multicolumn{3}{|c|}{ Time After Release } & \multicolumn{3}{|c|}{60} \\
\hline I.C. ${ }^{a}$ & F.v & C.F.\%oc & I.C. & F. & C.F.\% & I.C. & F. & C.F.\% \\
\hline $0.0-0.2$ & 9 & 3.0 & $0.1-0.7$ & 7 & 2.4 & $0.0-0.9$ & 1 & 0.3 \\
\hline $0.3-0.5$ & 11 & 6.8 & $0.8-1.4$ & 14 & 7.1 & $1.0-1.9$ & 15 & 5.4 \\
\hline $0.6-0.8$ & 33 & 17.9 & $1.5-2.1$ & 34 & 18.6 & $2.0-2.9$ & 17 & 11.1 \\
\hline $0.9-1.1$ & 33 & 29.1 & $2.2-2.8$ & 41 & 32.4 & $3.0-3.9$ & 37 & 23.6 \\
\hline $1.2-1.4$ & 48 & 45.3 & $2.9-3.5$ & 54 & 50.6 & $4.0-4.9$ & 42 & 37.8 \\
\hline $1.5-1.7$ & 42 & 59.5 & $3.6-4.2$ & 36 & 62.8 & $5.0-5.9$ & 48 & 54.0 \\
\hline $1.8-2.0$ & 35 & 71.3 & $4.3-4.9$ & 53 & 80.8 & $6.0-6.9$ & 48 & 70.3 \\
\hline $2.1-2.3$ & 34 & 82.7 & $5.0-5.6$ & 30 & 91.0 & $7.0-7.9$ & 43 & 84.8 \\
\hline $2.4-2.6$ & 26 & 91.5 & $5.7-6.3$ & 14 & 95.6 & $8.0-8.9$ & 26 & 93.5 \\
\hline $2.7-2.9$ & 9 & 94.5 & $6.4-7.0$ & 6 & 97.6 & $9.0-9.9$ & 8 & 96.2 \\
\hline $3.0-3.2$ & 4 & 96.0 & $7.1-7.7$ & 5 & 99.3 & $10.0-10.9$ & 7 & 98.6 \\
\hline $3.3-3.5$ & 5 & 97.6 & $7.8-8.4$ & 1 & 99.7 & $11.0-11.9$ & 4 & 100.0 \\
\hline $3.6-3.8$ & 4 & 99.0 & $8.5-9.1$ & 1 & 100.0 & & & \\
\hline $3.9-4.1$ & 1 & 99.3 & $9.2-9.8$ & & & & & \\
\hline $4.2-4.4$ & 1 & 99.7 & & & & & & \\
\hline $4.5-4.7$ & 0 & 99.7 & & & & & & \\
\hline $4.8-5.0$ & 1 & 100.0 & & & & & & \\
\hline Sum & 296 & - & - & 296 & - & $-\quad-$ & 296 & - \\
\hline
\end{tabular}


TABLE 16 (Cont'd.)

Frequency Distributions of Residual Increment of Spruce in the Mature Stands at Complete Periods Subsequent to Release.

\begin{tabular}{|c|c|c|c|c|c|c|c|c|}
\hline \multicolumn{9}{|c|}{ Time After Release } \\
\hline \multicolumn{2}{|r|}{80} & C.F.\% & \multicolumn{3}{|c|}{100} & I.C. & $\begin{array}{l}120 \\
\text { F. }\end{array}$ & C.F.\% \\
\hline $0.0-0.9$ & 1 & 0.3 & $1.0-1.9$ & & & $1.6-2.5$ & 1 & 0.3 \\
\hline $1.0-1.9$ & 6 & 2.4 & $2.0-2.9$ & 10 & 3.4 & $2.6-3.5$ & 8 & 3.0 \\
\hline $2.0-2.9$ & 13 & 6.8 & $3.0-3.9$ & 9 & 6.4 & $3.6-4.5$ & 5 & 4.7 \\
\hline $3.0-3.9$ & 13 & 11.2 & $4.0-4.9$ & 16 & 11.8 & $4.6-5.5$ & 16 & 10.1 \\
\hline $4.0-4.9$ & 28 & 20.6 & $5.0-5.9$ & 18 & 17.9 & $5.6-6.5$ & 11 & 13.8 \\
\hline $5.0-5.9$ & 31 & 31.1 & $6.0-6.9$ & 30 & 28.1 & $6.6-7.5$ & 27 & 23.0 \\
\hline $6.0-6.9$ & 36 & 43.2 & $7.0-7.9$ & 26 & 36.8 & $7.6-8.5$ & 20 & 29.8 \\
\hline $7.0-7.9$ & 39 & 56.4 & $8.0-8.9$ & 38 & 49.7 & $8.6-9.5$ & 31 & 40.2 \\
\hline $8.0-8.9$ & 44 & 71.3 & $9.0-9.9$ & 32 & 60.5 & $9.6-10.5$ & 29 & 50.0 \\
\hline $9.0-9.9$ & 37 & 83.8 & $10.0-10.9$ & 38 & 73.3 & $10.6-11.5$ & 35 & 61.8 \\
\hline $10.0-10.9$ & 22 & 91.2 & $11.0-11.9$ & 34 & 84.8 & $11.6-12.5$ & 29 & 71.6 \\
\hline $11.0-11.9$ & 8 & 94.0 & $12.0-12.9$ & 16 & 90.2 & $12.6-13.5$ & 30 & 81.7 \\
\hline $12.0-12.9$ & 13 & 98.3 & $13.0-13.9$ & 8 & 93.0 & $13.6-14.5$ & 14 & 86.5 \\
\hline $13.0-13.9$ & 3 & 99.4 & $14.0-14.9$ & 11 & 96.6 & $14.6-15.5$ & 14 & 91.2 \\
\hline \multirow[t]{5}{*}{$14.0-14.9$} & 2 & 100.0 & $15.0-15.9$ & 8 & 99.3 & $15.6-16.5$ & $\mathbf{5}$ & 92.8 \\
\hline & & & $16.0-16.9$ & 1 & 99.7 & $16.6-17.5$ & 14 & 97.6 \\
\hline & & & $17.0-17.9$ & 1 & 100.0 & $17.6-18.5$ & 5 & 99.3 \\
\hline & & & & & & $18.6-19.5$ & 0 & 99.3 \\
\hline & & & & & & $19.6-20.5$ & 2 & 100.0 \\
\hline Sum & 296 & - & - & 296 & - & - & 296 & 一 \\
\hline
\end{tabular}

Similar data of residual increment for the cut-over stands for a period of 15 years after cutting are also plotted in the same figure. A straight line fits the points in this case also indicating that this distribution is normal when confined above the zero limit. From the evidence at hand it seems reasonable to assume that the residual increment distributions of the cut-over stands will continue to be normal; so that, knowing the mean and the standard deviation of residual increment at any time subsequent to cutting, the frequencies of the distribution may be readily computed from normal probability tables.

It must be recognized however, that if the straight lines of Fig. 13 were extended to the left beyond the zero increment ordinate, small percentage values of negative increment would be obtained. Negative increments are, of course, practically impossible, so that the distributions must be limited to zero. In calculating theoretical distributions for given means and given standard deviations, any negative increments resulting must be thrown into the 
lowest increment class above zero. Such occurrences, falling as they do at the extreme end of the distribution, would form such a small percentage of the whole distribution that their effect on the calculation of tree distributions and yields as made in this report would be negligible.

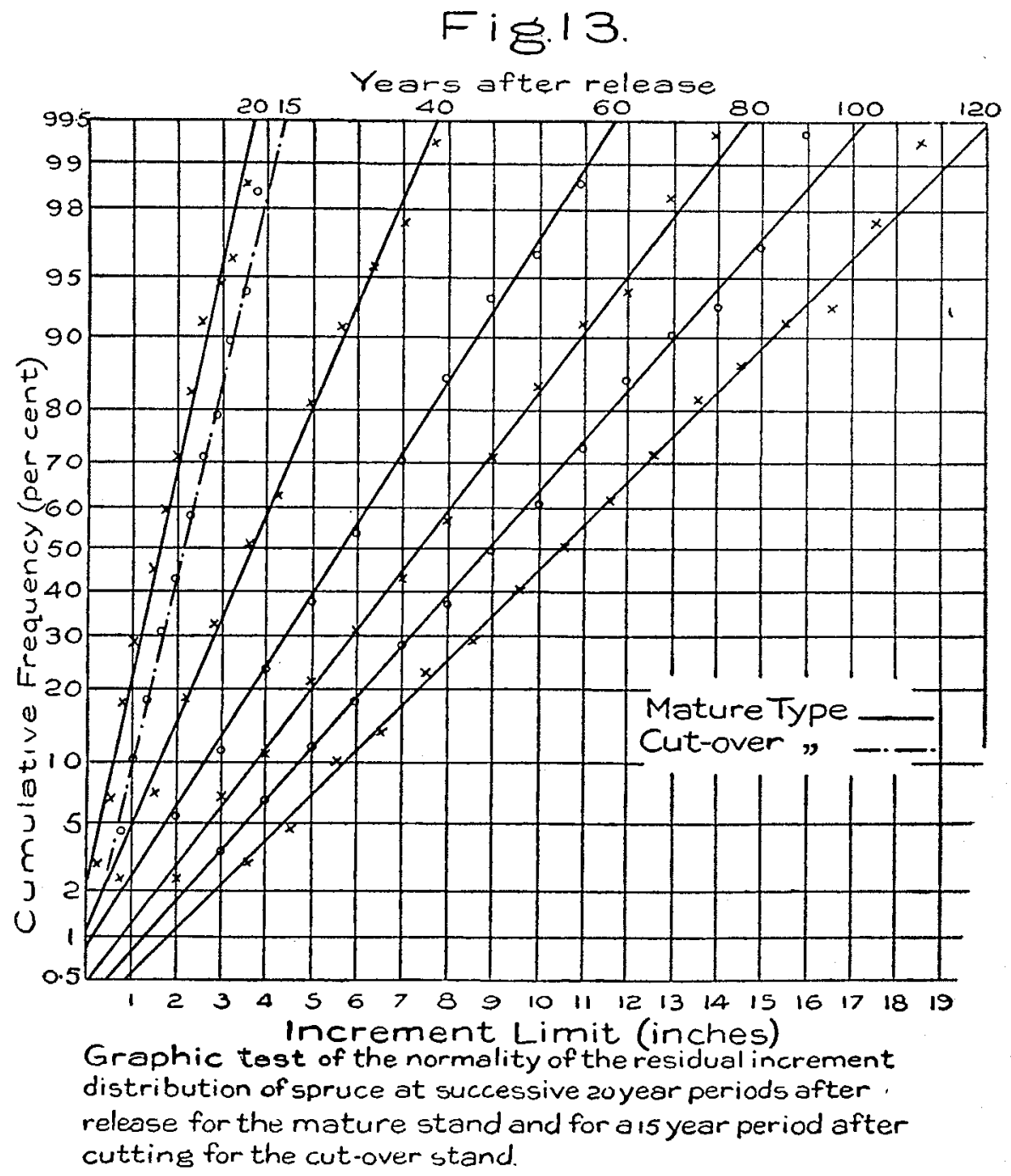


APPENDIX III.

THE DEVELOPMENT OF THE STANDARD DEVIATION OF

RESIDULAL INCREMENT IN CUT-OVER STANDS

It was shown on page 430 that the standard deviation of residual increment differed to some extent in the cut-over and mature uncut stands. For the mean increment of 2.1 inches immediately following release the values were \pm .82 inches and \pm 1.00 inches respectively, giving a coefficient of variation of \pm 39 and \pm 48

As the cut-over stand approaches maturity and full stocking again, its development should become similar to that of the present mature stand. It may be assumed therefore that the standard deviation or the coefficient of variation of residual increment in the cut-over stands corresponding to a given mean increment for a period at maturity will approach the standard deviation or the coefficient of variation of the mature stand for the same amount of mean increment at a mature period. In other words the standard deviation or coefficient of variation of a 2 inch mean increment at 100 years or more after release should be about the same in both cut'over and mature uncut stands. For intermediate 2 inch mean increments below 100 years the standard deviation or coefficient of variation of the cut-over should gradually approach the values of the mature stand.

TABLE 17

Statistics of the Residual Increment of Spruce of Mature Stands for Successive 20 year Periods and for Complete Periods Following Release.

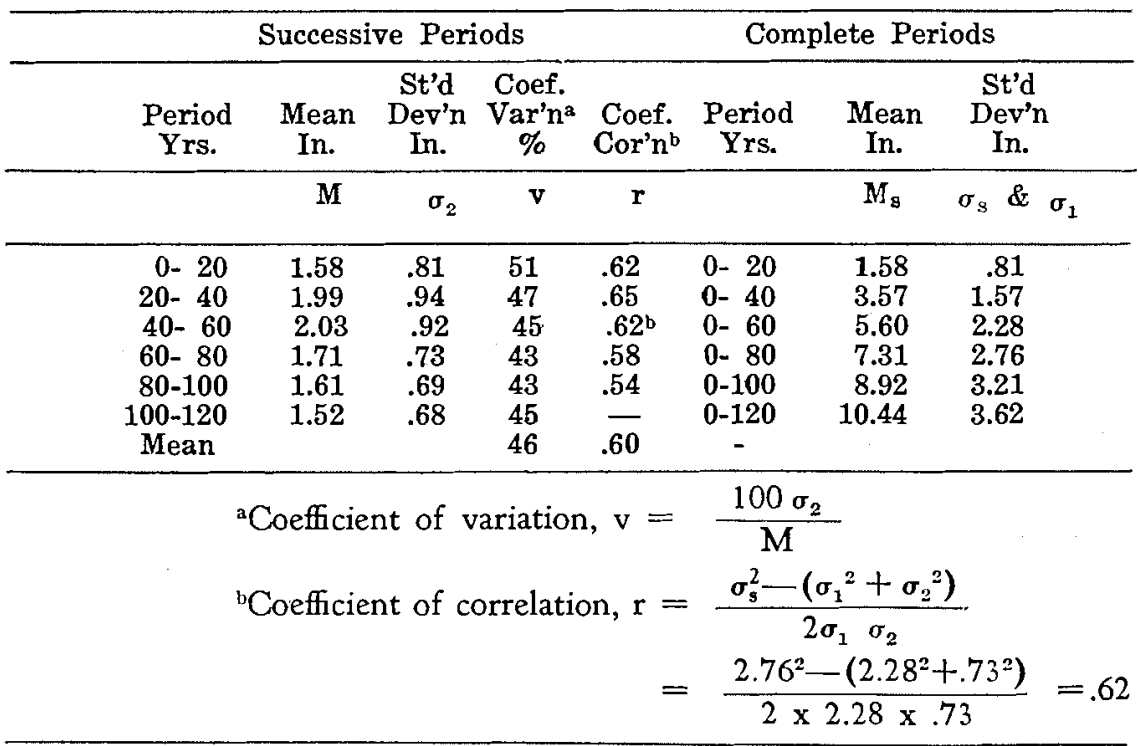


In Table 17 the mean, standard deviation and coefficient of variation are shown for the native stand for successive 20 year periods after release. It will be noted that the coefficient of variation is nearly constant over all periods with a mean value of 46 . The coefficient of variation in the cut-over stands may therefore be expected to increase from 39 in initial growth periods to 46 in mature growth periods. Values of the coefficient of variation for the cut-over stand in intermediate growth periods were estimated by drawing a curve through the abscissa of 39 at the 1 st 2 inch mean increment to become tangent to the 46 abscissa at the 5 th 2 inches of mean increment. The estimated values of the coefficient of variation for successive 2 inch mean increments, together with the standard deviations calculated therefrom are tabulated in Table 18.

TABLE 18

Statistics of the Residual Increment of Spruce of Cut-over Stands for Successive 2 inch Increments and for Complete Increments Following Release.

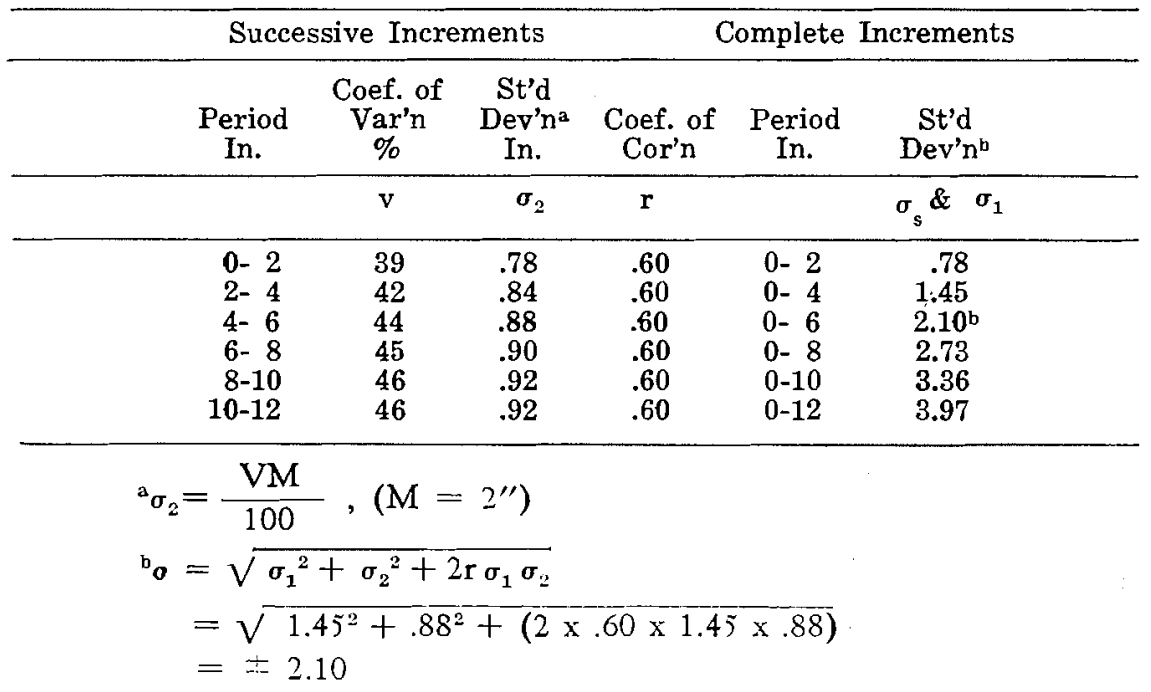

It is the standard deviation of the sum of the successive 2 inch increment distributions that is sought, that is, the standard deviation of the distribution corresponding to $2,4,6,8,10,12$, etc. inches of mean increment. In order to estimate the standard deviation of the sums it is necessary to evaluate the coefficient of correlation between the successive periodic distributions. Knowing $r$, the coefficient of correlation, the standard deviation of the sum may be calculated from the equation,

$$
\sigma_{\mathrm{s}}^{2}=\sigma_{1}^{2}+\sigma_{2}^{2}+2 \mathrm{r} \sigma_{1} \sigma_{2}
$$


In the native stands the standard deviations of the distribution of the sums and of successive 20 year periods have been calculated on page 454 and above respectively. The coefficient of correlation between the successive 20 year distributions may therefore be calculated by substituting the values of $\sigma^{3}$, $\sigma_{1}$ and $\sigma_{2}$ in the equation above and solving for $r$. The values of $r$ so obtained between successive 20 year distributions are given in Table 17. The values are nearly constant with a mean of .60 .

If a value of .60 be assumed for the relationship between the successive 2 inch distributions of the cut-over stand, the value of the standard deviations of their sums are readily calculated. The results are given in Table 18.

Some examples may lead to a clearer understanding of the procedure. From Table 18 it is found that for the first 2 inches of mean residual increment the standard deviation is \pm .78 inches. This value is also the standard deviation for a total residual mean increment of 2 inches after release and is recorded in the sixth column of Table 18 as $\sigma_{a}$. For the second 2 inches of mean increment the standard deviation, $\sigma_{2}$, is \pm .84 , while for the first 2 inches of increment it was \pm .78 which becomes $\sigma_{1}$, in calculating the standard deviation or $\sigma_{s}$ for a complete increment of 4 inches after release. The coefficient of correlation $\mathrm{r}$, between $\sigma_{1}$, and $\sigma_{2}$ is .60 , and substi, tuting these values in the equation we have:

$$
\begin{aligned}
& \sigma_{s}^{2}=.78^{2}+.84^{2}+(2 \times .60 \times .78 \times .84) \\
& \text { and } \\
& \sigma_{s}= \pm 1.45
\end{aligned}
$$

For a complete increment of 6 inches we have:

$\sigma_{1}= \pm 1.45$, or $\sigma_{\mathrm{s}}$ for 4 inches of increment.

$\sigma_{2}= \pm .88$

$\vec{r}=.60$

and by substitution,

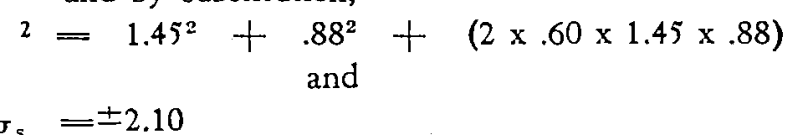




\section{LITERATURE CITED}

(1) Forest Branch. 1934. Annual Report, Dept. of Lands. P. 10.

(2) Dickson, F. 1927. A Study of Heart Rot in the Amabilis fir (Abies amabilis) in the Upper Fraser Region of British Columbia. Unpublished Report. British Columbia Forest Service.

(3) Barr, P.M. 1930. The Effect of Soil Moisture on the Establishment of Spruce Reproduction in British Columbia. Yale Univ. School of Forestry Bull. 26.

(4) 1933. Ecological Aspects of Spruce Regeneration. Records of Fifth Pacific Science Congress. 4001-7.

(5) Griffith, B.G. 1931. The Natural Regeneration of Spruce in Central British Columbia. For. Chron. 7: 199-219.

(6) Graham, A. 1935. The Present Position of Forest Management, Protection and Silviculture in Canada. For. Chron. 11: 123-132.

(7) Baker, F. S. 1934. Theory and Practice of Silviculture New York and London. 1st ed. McGraw-Hill Book Co. Inc. Pp XIV-502.

(8) Dwight, T.W. 1929. Letter regarding Growth of Unevenaged Stands. British Columbia Forest Service. File 080302.

(9) 1926. Use of Growth Charts in Place of Yield Tables. Jour. For. 24: 358-377. 